\title{
Autologous endothelial progenitor cell therapy improves right ventricular function in a model of chronic thromboembolic pulmonary hypertension
}

Fanny Loisel, MSc, ${ }^{\mathrm{a}, \mathrm{b}}$ Bastien Provost, MD, MSc, ${ }^{\mathrm{a}}$ Julien Guihaire, MD, PhD, ${ }^{\mathrm{a}, \mathrm{c}}$ David Boulate, MD, ${ }^{\mathrm{a}, \mathrm{d}}$ Nassim Arouche, Eng, ${ }^{\mathrm{b}}$ Myriam Amsallem, MD, ${ }^{\mathrm{a}}$ Jennifer Arthur-Ataam, PhD, ${ }^{a}$ Benoît Decante, MSc, ${ }^{\mathrm{a}}$ Peter Dorfmüller, MD, PhD, ${ }^{\mathrm{a}, \mathrm{e}}$ Elie Fadel, $\mathrm{MD}, \mathrm{PhD},{ }^{\mathrm{a}, \mathrm{d}, \mathrm{f}}$ Georges Uzan, $\mathrm{PhD},{ }^{\mathrm{b}}$ and Olaf Mercier, $\mathrm{MD}, \mathrm{PhD}^{\mathrm{a}, \mathrm{d}, \mathrm{f}}$

\section{ABSTRACT}

Background: Right ventricular (RV) failure is the main prognostic factor in pulmonary hypertension, and ventricular capillary density (CD) has been reported to be a marker of RV maladaptive remodeling and failure. Our aim was to determine whether right intracoronary endothelial progenitor cell (EPC) infusion can improve RV function and $\mathrm{CD}$ in a piglet model of chronic thromboembolic pulmonary hypertension (CTEPH).

Methods: We compared 3 groups: sham $(n=5)$, CTEPH $(n=6)$, and CTEPH with EPC infusion (CTEPH+EPC; $\mathrm{n}=5)$. After EPC isolation from $\mathrm{CTEPH}+\mathrm{EPC}$ piglet peripheral blood samples at 3 weeks, the CTEPH and sham groups underwent right intracoronary infusion of saline, and the $\mathrm{CTEPH}+\mathrm{EPC}$ group received EPCs at 6 weeks. RV function, pulmonary hemodynamics, and myocardial morphometry were investigated in the animals at 10 weeks.

Results: After EPC administration, the RV fractional area change increased from $32.75 \%$ (interquartile range [IQR], 29.5\%-36.5\%) to 39\% (IQR, 37.25\%$46.50 \% ; P=.030$ ). The CTEPH+EPC piglets had reduced cardiomyocyte surface areas (from $298.3 \mu \mathrm{m}^{2}$ [IQR, 277.4-335.3 $\mu \mathrm{m}^{2}$ ] to $234.6 \mu \mathrm{m}^{2}$ (IQR, 211.1-264.7 $\mu \mathrm{m}^{2} ; P=.017$ ), and increased CD31 expression (from 3.12 [IQR, 1.27-5.09] to 7.14 [IQR, 5.56-8.41; $P=.017$ ). EPCs were found in the RV free wall at 4 and 24 hours after injection but not 4 weeks later.

Conclusions: Intracoronary infusion of EPC improved RV function and CD in a piglet model of CTEPH. This novel cell-based therapy might represent a promising RV-targeted treatment in patients with pulmonary hypertension. (J Thorac Cardiovasc Surg 2019;157:655-66)

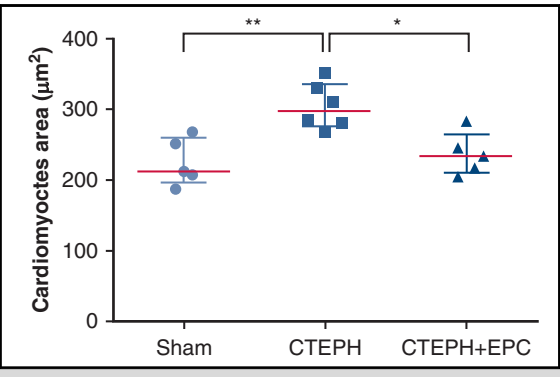

Decreased cardiomyocyte surface area after right intracoronary administration of endothelial progenitor cells in a chronic thromboembolic pulmonary hypertension pig model.

\section{Central Message}

Coronary infusion of autologous endothelial progenitor cells improved right ventricle adaptation to pulmonary hypertension in an animal model of chronic thromboembolic pulmonary hypertension.

\section{Perspective}

Pulmonary hypertension is a life-threatening disease that leads to right ventricle failure. To date, pharmacological advances have targeted the pulmonary circulation. We report that right ventricle-targeted cell therapy might hold promise in supporting right ventricular function in a model of chronic thromboembolic pulmonary hypertension.

See Editorial Commentary page 667

\footnotetext{
From the ${ }^{a}$ Research and Innovation Unit, Inserm UMR-S 999, ${ }^{c}$ Department of Cardiac Surgery, ${ }^{\mathrm{d}}$ Department of Thoracic and Vascular Surgery and Heart-Lung Transplantation, Marie Lannelongue Hospital, ${ }^{\mathrm{e}}$ Department of Pathology, ${ }^{\mathrm{b}}$ Inserm 1197 Research Unit, Univ Paris Sud, Paris-Saclay University, Le Plessis Robinson, France; and ${ }^{\mathrm{f}}$ Paris-Sud University and Paris-Saclay University, School of Medicine, Kremlin-Bicêtre, France.

This work was supported by a public grant overseen by the French National Research Agency as part of the second "Investissement d'Avenir" program (reference: ANR-15-RHUS-0002).

Drs Loisel and Provost contributed equally to this work.
}

Received for publication Feb 11, 2018; revisions received July 31, 2018; accepted for publication Aug 1, 2018.

Address for reprints: Olaf Mercier, MD, PhD, Department of Thoracic and Vascular Surgery and Heart-Lung Transplantation, Research and Innovation Unit, Marie Lannelongue Hospital, 133 Ave de la Resistance, 92350 Le Plessis Robinson, France (E-mail: o.mercier@ccml.fr). 0022-5223/\$36.00

Copyright (C) 2018 by The American Association for Thoracic Surgery https://doi.org/10.1016/j.jtcvs.2018.08.083 


$\begin{array}{ll}\text { Abbreviations and Acronyms } \\ \text { Ac-LDL } & =\text { acetylated low-density lipoprotein } \\ \text { BrdU } & =\text { bromodeoxyuridine } \\ \text { CTEPH } & =\text { chronic thromboembolic } \\ & \text { pulmonary hypertension } \\ \text { CTEPH+EPC }=\text { chronic thromboembolic } & \text { pulmonary hypertension with } \\ & \text { endothelial progenitor cell } \\ & \text { infusion } \\ \text { Ea } & =\text { arterial elastance } \\ \text { Ees } & =\text { end-systolic elastance } \\ \text { EPC } & =\text { endothelial progenitor cell } \\ \text { GAPDH } & =\text { glyceraldehyde-3-phosphate } \\ & \text { dehydrogenase } \\ \text { GFP } & =\text { green fluorescent protein } \\ \text { IGF } & =\text { insulin growth factor } \\ \text { IQR } & =\text { interquartile range } \\ \text { MHC } & =\text { myosin heavy chain } \\ \text { mPAP } & =\text { mean pulmonary artery pressure } \\ \text { PA } & =\text { pulmonary artery } \\ \text { PBS } & =\text { phosphate-buffered saline } \\ \text { PFA } & =\text { paraformaldehyde } \\ \text { PH } & =\text { pulmonary hypertension } \\ \text { RUL } & =\text { right upper lobe } \\ \text { RV } & =\text { right ventricular } \\ \text { RVFAC } & =\text { right ventricular fractional area } \\ & \text { change } \\ \text { T0 } & =\text { baseline } \\ \text { T6 } & =6 \text { weeks } \\ \text { T10 } & =10 \text { weeks } \\ \text { TAPSE } & =\text { tricuspid annular plane systolic } \\ \text { TPR } & =\text { excursion } \\ \text { VEGF } & =\text { vascular endothelial growth factor } \\ & \end{array}$

\begin{tabular}{|l} 
(U) $\begin{array}{l}\text { Scanning this QR code will } \\
\text { take you to the article title } \\
\text { page to access supplementary } \\
\text { information. }\end{array}$ \\
\end{tabular}

Right ventricular (RV) function is the main prognostic factor in pulmonary hypertension $(\mathrm{PH}) .{ }^{1}$ Increased pulmonary vascular resistance induces RV remodeling from an adaptive to a maladaptive phenotype as the disease progresses. Unlike adaptive remodeling, maladaptive RV remodeling is characterized by dilatation, reduced cardiac output, ventriculoarterial uncoupling, and a high mortality rate. At the cellular level, maladaptive remodeling is associated with reduced angiogenesis, increased fibrosis, metabolic changes, and a dysregulation of the autonomic nervous system. ${ }^{2,3}$ The transition from adaptive to maladaptive RV remodeling is a continuum that ultimately leads to endstage heart failure.

A decrease in ventricular capillary density occurs in various animal models of $\mathrm{PH}^{4,5}$ and in humans at the stage of maladaptive remodeling or heart failure. ${ }^{6}$ Indeed, $\mathrm{RV}$ ischemia has been described by Gómez and colleagues in the setting of chronic $\mathrm{PH}^{7}$ To date, no cell-based therapy is available for the overloaded right ventricle. Therefore, endothelial progenitor cells (EPCs) might be good candidates for RV-targeted therapy because they can differentiate into specialized endothelial cells ${ }^{8}$ and they release paracrine factors involved in angiogenesis. ${ }^{9}$ EPCs have been reported to promote vascular repair and angiogenesis, ${ }^{10-12}$ although they have not yet been investigated in $\mathrm{PH}$.

Chronic thromboembolic PH (CTEPH) is characterized by chronic pulmonary vessel obstruction combined with severe distal vasculopathy. ${ }^{13}$ Our group developed a novel piglet model of CTEPH that has been validated for RV dysfunction and pulmonary vascular disease. ${ }^{14,15}$ We reported that ventricular-arterial uncoupling can be durably reversed when the RV afterload is normalized in this large-animal model. ${ }^{16}$ Moreover, the RV capillary density is impaired in long-term CTEPH animal models. ${ }^{17}$ Consequently, our aim was to investigate the effect of right intracoronary administration of EPCs on RV function and capillary density. Our hypothesis was that EPC would improve RV function by enhancing capillary density.

\section{METHODS \\ CTEPH Model}

Five-week-old large white piglets, weighing 20-22 kg, were included in the preliminary $(\mathrm{n}=2)$ and the main study $(\mathrm{n}=16)$. The animals were randomly assigned to the sham or CTEPH group. To establish the CTEPH model, the piglets were first subjected to surgery under general anesthesia (propofol, isoflurane, and pancuronium) and mechanical ventilation, and they underwent a ligation of the left pulmonary artery (PA) through a left thoracotomy. Embolization of the right PA was then performed weekly over a 5-week period, via percutaneous access to the brachiocephalic vein, using cyanoacrylate glue (Histoacryl; B. Braun, Melsungen, Germany), to target the right lower lobe. ${ }^{14}$ Thus, ligation of the left PA, combined with selective occlusion of the distal arteries of the right lower lobe, gradually increased the pulmonary vascular resistance, thereby leading to RV dysfunction at 5 weeks. The animals in the sham group underwent a thoracotomy and weekly right PA saline injections over a 5-week period to mimic the embolization of the animals in the CTEPH group.

A preliminary pilot study was undertaken using 1 sham piglet in which GFP-labeled EPCs were administrated at 6 weeks (T6), and the animal was sacrificed 4 hours later. One CTEPH piglet received GFP-labeled EPCs at T6 and it was sacrificed 24 hours later.

Sixteen piglets were included in the main study: 5 sham, 6 CTEPH, and 5 CTEPH+EPC (Figure 1, A). At T6, the animals in the sham and the CTEPH groups received a right intracoronary injection of saline, whereas the animals in the CTEPH+EPC group each received $16 \pm 3.21$ million 


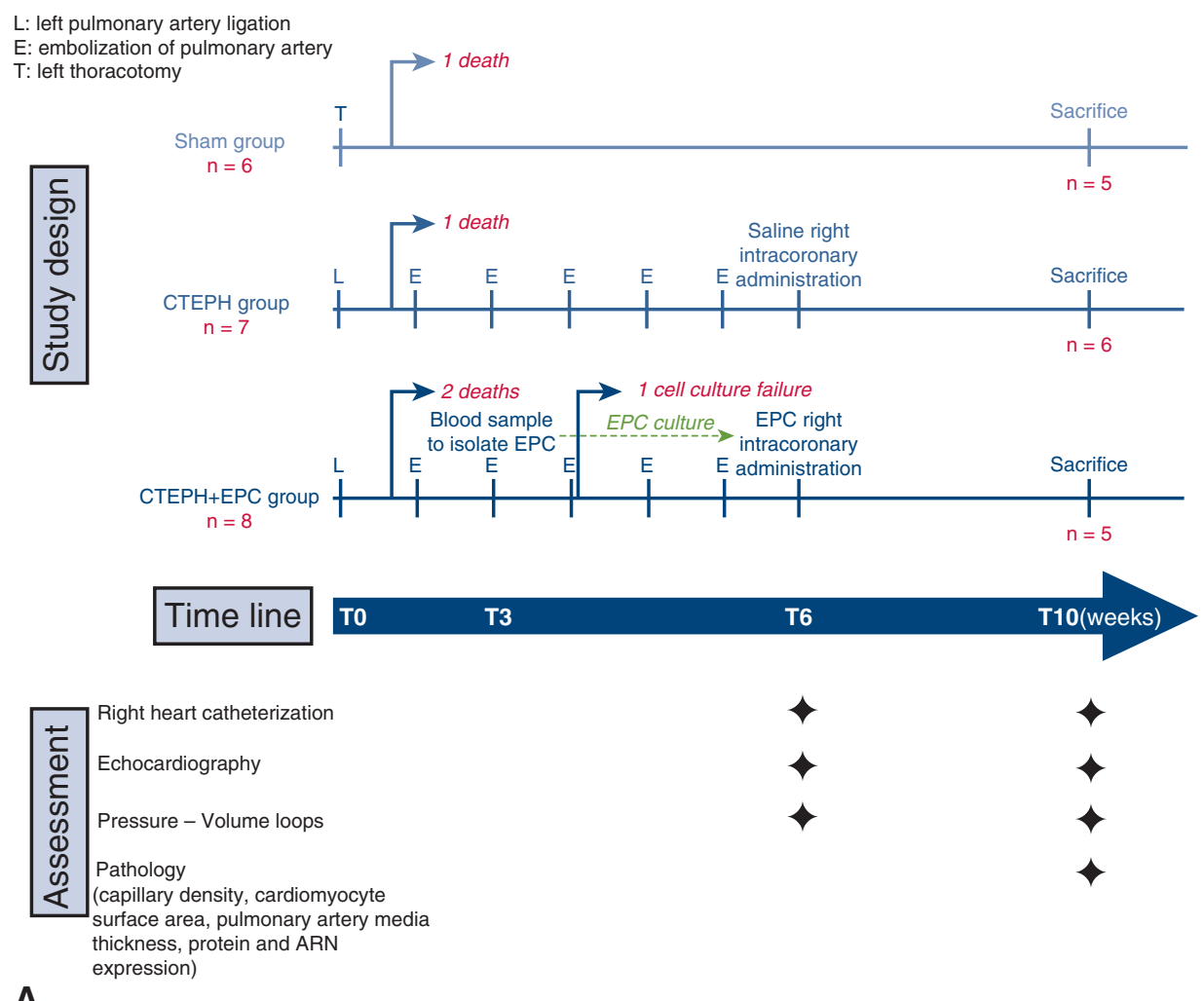

A

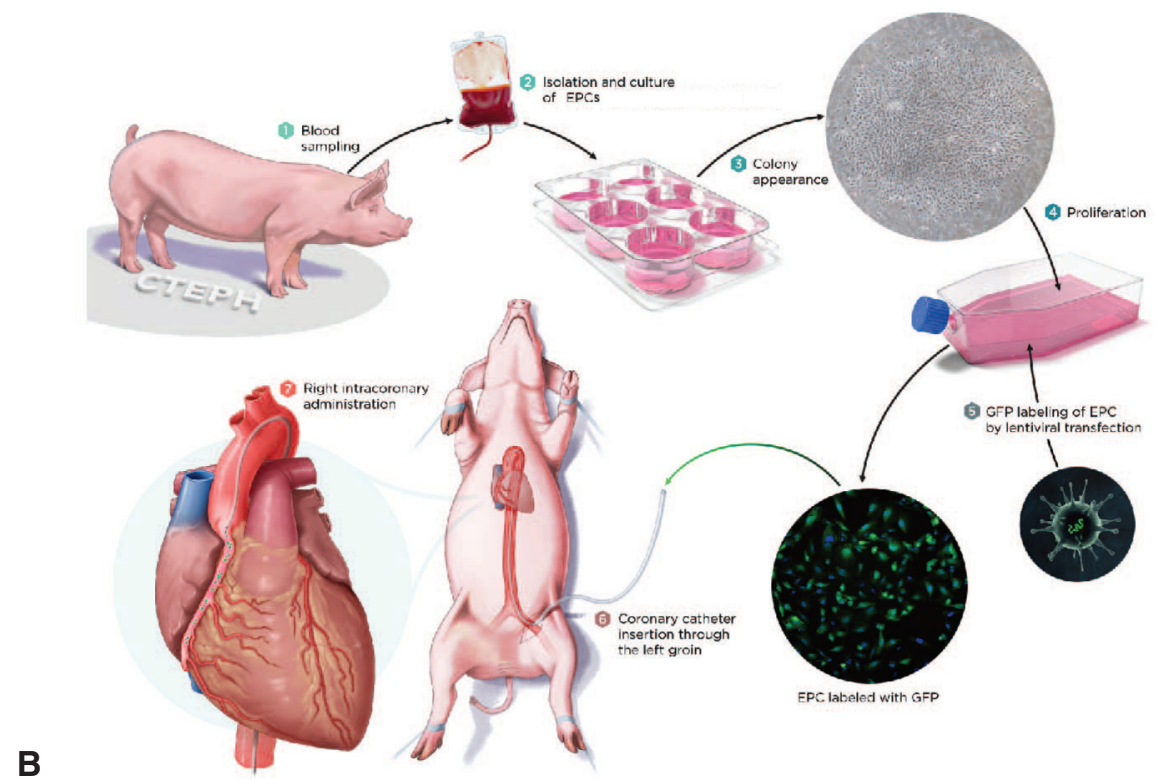

FIGURE 1. A, Study design. B, Study design for endothelial progenitor cell (EPC) administration in piglets of the chronic thromboembolic pulmonary hypertension and endothelial progenitor cell infusion $(C T E P H+E P C)$ group. CTEPH, Chronic thromboembolic pulmonary hypertension; GFP, Green fluorescent protein.

GFP-labeled EPCs (an average of $6.5 \times 10^{4} \mathrm{EPC} / \mathrm{kg}$; Figure $1, B$ ). Animals entering the CTEPH procedure were randomly assigned to either the CTEPH or the CTEPH+EPC group at the time that the model was established, just before left PA ligation.

\section{EPC Administration}

Cell therapy administration was performed at $\mathrm{T} 6$ for the CTEPH+EPC group. This time point was chosen because it has been proven in the study of Mercier and colleagues that chronic PH is developed in pigs 5 weeks 


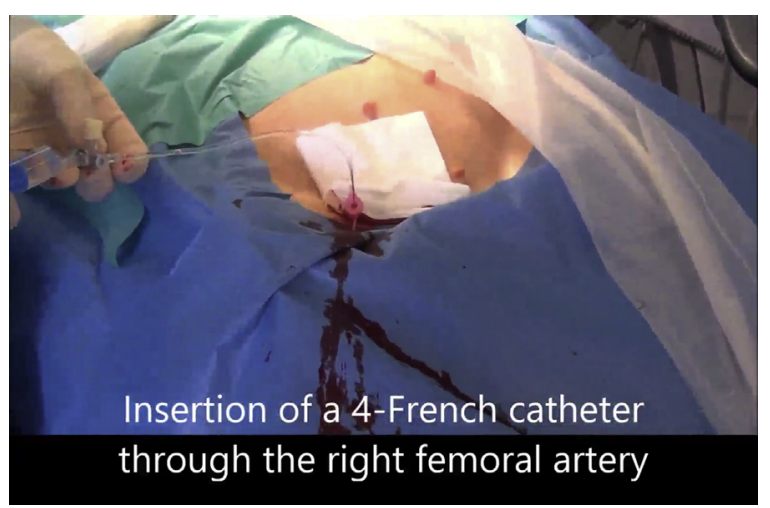

VIDEO 1. Description of the right intracoronary EPCs administration procedure in a piglet model of CTEPH. Video available at: https://www.jtcvs. org/article/S0022-5223(18)32477-2/fulltext.

after left PA ligature and weekly embolization. ${ }^{14}$ EPC administration was performed under general anesthesia, using a 4-French catheter inserted through the femoral artery and an AR I mod catheter (Cordis, Hialeah, Fla) placed in the proximal right coronary artery, under fluoroscopic guidance. Proper positioning of the catheter was assessed using injection of contrast agent. Autologous EPCs were resuspended in $20 \mathrm{~mL}$ of saline solution in a syringe, and injected continuously through the catheter into the right coronary artery at a rate of $6.6 \mathrm{~mL} / \mathrm{min}$. Each piglet in the CTEPH+EPC group was injected with the maximum number of cells available after culturing for no more than 4 passages. For more details, refer to Video 1.

\section{Hemodynamic Assessment}

The heart rate, the mean PA pressure (mPAP), cardiac output, and blood saturation were measured at baseline (T0), at T6, and at 10 weeks (T10). A pressure-volume loop analysis of the RV was performed at T6 and T10 with a conductance VentriCath 507 (Millar Instruments, Houston, Tex).

\section{Echocardiographic Assessment}

Transthoracic echocardiography (Vivid E9; GE Medical Systems, Milwaukee, Wis) was performed at T0, T6, and T10. Tricuspid annular plane systolic excursion (TAPSE), RV fractional area change (RVFAC), and the $\mathrm{RV}$ free wall strain were assessed. ${ }^{18}$ Measurements were analyzed by 2 blinded cardiologists.

\section{Capillary Density Assessment in the Right Ventricle}

To assess the capillary density, RV samples were incubated with a rabbit anti-human CD31 (CD31 clone 1A10; 1:100; Diagomics, Blagnac, France) detected using ultraView Universal DAB Detection Kit (Ventana Medical Systems, Oro Valley, Ariz) staining with Benchmark GX (Roche, Boulogne-Billancourt, France). The capillary density was determined according to the number of capillaries per square millimeter in 5 fields of view for each animal at $400 \times$ magnification (NIS-Element software; Nikon, Tokyo, Japan).

\section{Cardiomyocyte Surface Assessment in the Right Ventricle}

Right ventricle samples were incubated with wheat germ agglutinin (WGA-AF488; Invitrogen, Carlsbad, Calif; $10 \mu \mathrm{g} / \mathrm{mL}$ ) and 4',6-diamidino-2-phenylindole (1:10,000; Sigma-Aldrich, St Louis, Mo). The cardiomyocyte surface was determined, as previously described, ${ }^{19}$ using Image J software (open source) in 15 fields for each animal captured at $630 \times$ magnification (NIS-Element software).

\section{Statistical Analysis}

Data from the 3 groups were compared with the Kruskal-Wallis test, and the groups were compared 2 by 2 with the Mann-Whitney test in case of a significant Kruskal-Wallis test. The results are presented as median (interquartile range [IQR]). Statistical analyses were performed using Prism 6 software (GraphPad, San Diego, Calif). See Appendix 1 and Figure E1 and Figure E2 for more details.

\section{RESULTS}

\section{Preliminary Study}

The aim of the preliminary study was to evaluate the feasibility and safety of right intracoronary administration of EPCs in piglets. We observed neither ischemic areas, perivascular inflammatory infiltrates, nor scarring in the tissue (data not shown). A sham piglet was sacrificed at 4 hours and a CTEPH piglet was sacrificed at 24 hours after receiving EPCs through the right coronary artery. Immunohistological analysis revealed the presence of EPCs in the $\mathrm{RV}$ myocardium and capillaries as well as in the right upper lobe (RUL; Figure 2). EPCs were also found in the spleen, albeit at a lower level (data not shown).

\section{Assessment at T6}

There was no difference in terms of body weight, body surface area, and hemodynamic data (mPAP, total pulmonary resistance [TPR], cardiac output, RVFAC, TAPSE, $\mathrm{RV}$ free wall strain, and end-systolic elastance [Ees]/arterial elastance [Ea] ratio) between the CTEPH and $\mathrm{CTEPH}+\mathrm{EPC}$ groups at T0 and at T6 (data not shown).

\section{Assessment of EPC Function}

Analysis of the EPC expression markers revealed no difference between the control EPCs and the CTEPH EPCs (Figure E3). In terms of EPC function, there was no difference between the control EPCs and the CTEPH EPCs in terms of acetylated low-density lipoprotein (Ac-LDL) uptake (Figure E4), wound healing closure (Figure E5), and proliferation (Figure E6, $A-C$ ).

\section{RV Function and Pulmonary Hemodynamics}

Intracoronary administration of EPCs in the CTEPH animals was determined to be safe and feasible (eg, no arrhythmia, myocardial infarction, or sudden death after the procedure). Pulmonary hemodynamic as well as RV function were stable during the experiment, and the cardiac troponin I blood level returned to within the normal range 4 weeks (T10) after EPC infusion (Figure E7).

At T10, the RVFAC was not significantly different between the sham (43.5\%; IQR, 33.75-45.48) and the CTEPH (32.7\%; IQR, 29.5-36.5) and the CTEPH+EPC groups (39\%; IQR, 37.25-46.5; sham vs CTEPH, $P=.125$ and sham vs CTEPH+EPC, $P=.889$ ). However, the RVFAC was significantly higher in the CTEPH+EPC group compared with the CTEPH group $(P=.030$; 

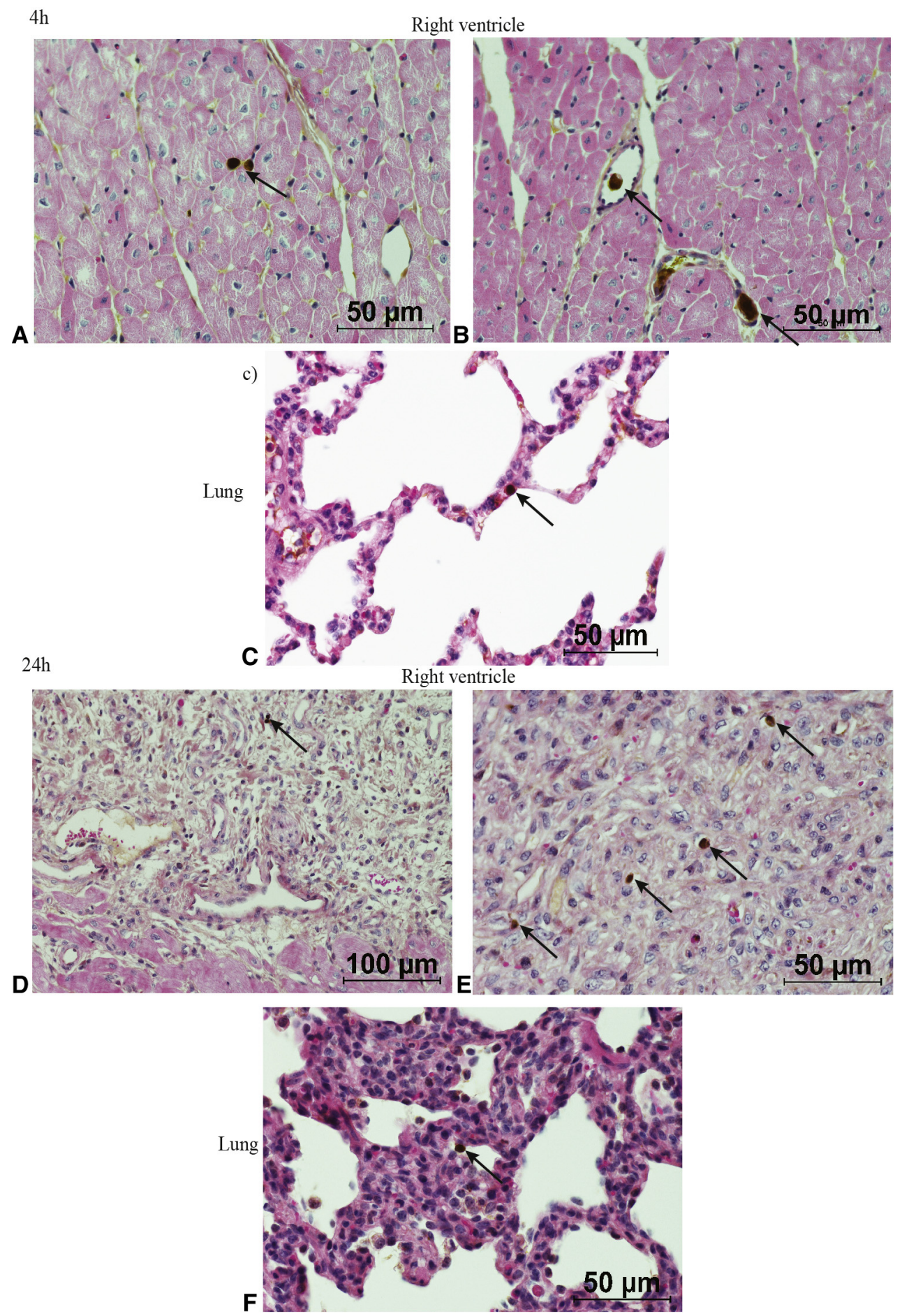

FIGURE 2. Proof of concept of endothelial progenitor cell (EPC) intracoronary administration. The location of the EPC/GFP-labeled cells was determined 4 hours after their administration in a sham pig (A, B, and C) and 24 hours after their administration in a chronic thromboembolic pulmonary hypertension pig (D, E, and F). Anti-GFP staining on HES sections revealed the presence of EPCs in right ventricle myocardium and capillaries (A and B) and in the right upper lobe (C), 4 hours after administration EPCs were found in the epicardium of the right ventricle (D and E) and in the right upper lobe (F) 24 hours after administration. Arrows indicate the presence of EPC. GFP, Green fluorescent protein. 

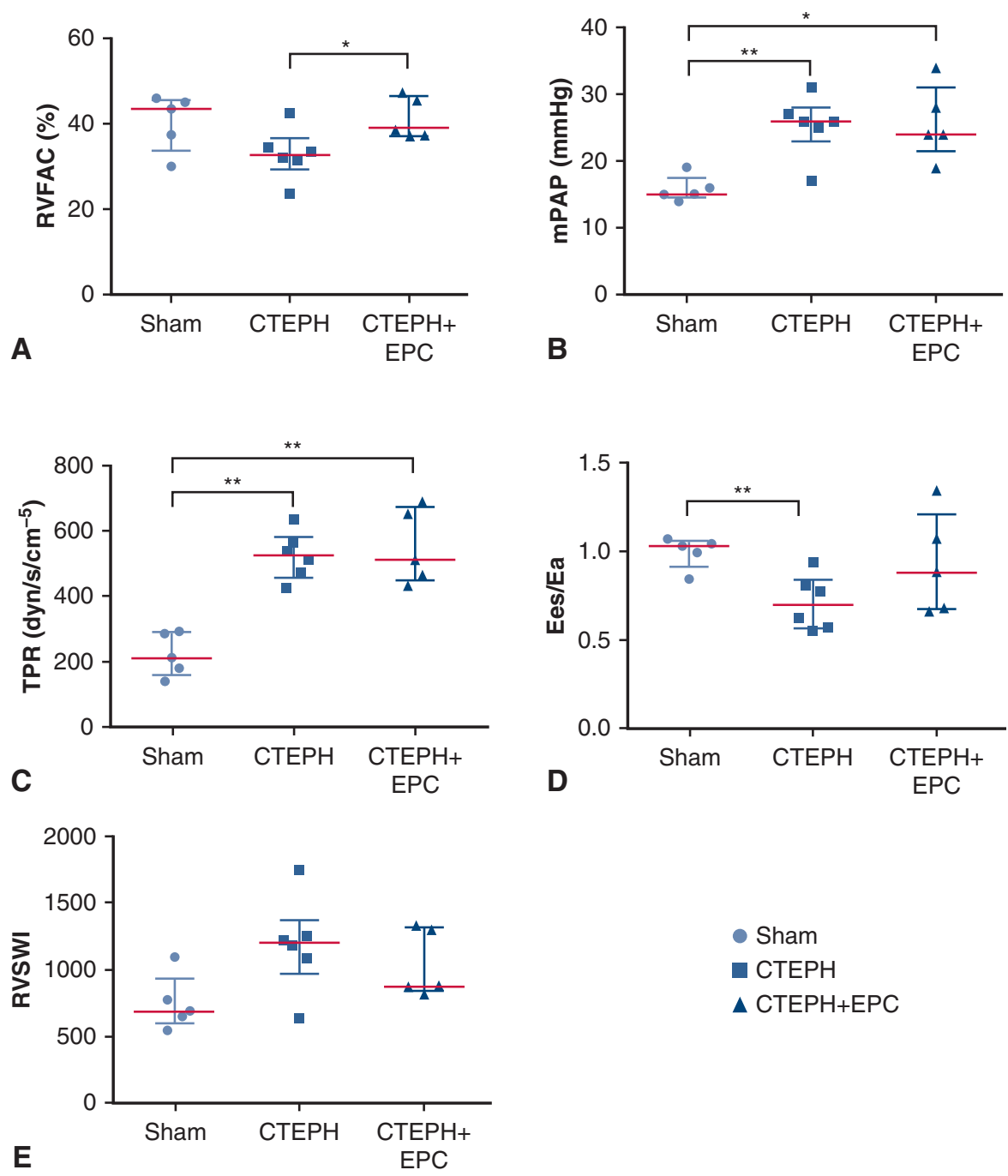

FIGURE 3. Right ventricle and lung function at T10. A, The assessment of the right ventricular fractional area change revealed an increase in RV contractility in the chronic thromboembolic pulmonary hypertension and endothelial progenitor cell infusion $(C T E P H+E P C)$ group compared with the chronic thromboembolic pulmonary hypertension $(C T E P H)$ group. Lung function was assessed by recording mean pulmonary arterial pressure $(m P A P)(\mathrm{B})$ and total pulmonary resistance $(T P R)(\mathrm{C})$, and it revealed an increase in these parameters in the CTEPH group and CTEPH+EPC group compared with the sham group. Right ventricle function assessed using pressure-volume loop revealed reduced ventriculoarterial coupling in the CTEPH group compared with the sham group (D). The right ventricular stroke work indexed ( $R V S W I$ ) did not differ between the groups (E). *P<.05, **P<.01. RVFAC, Right ventricular fractional area change; Ees/Ea, right ventricular to pulmonary artery coupling.

Figure $3, A$ ). TAPSE and RV free wall strain were higher in the sham group compared with the CTEPH group and the CTEPH+EPC group (TAPSE: $21 \mathrm{~mm}$; IQR, 19.5-21; $15.5 \mathrm{~mm}$; IQR,13.75-17.25, and $16 \mathrm{~mm}$; IQR, 15.5-17), respectively; sham versus CTEPH, $P=.009$ and sham versus $\mathrm{CTEPH}+\mathrm{EPC}, P=.007$; $\mathrm{RV}$ free wall strain: $33 \%$ (IQR, 28.6-36), 19.5\% (IQR, 15.5-27.25), and 24\% (IQR, 23.5-29), respectively; sham versus CTEPH, $P=.017$ and sham versus CTEPH+EPC, $P=.031$. However, the TAPSE and RV free wall strain were not statistically different between the CTEPH group and the $\mathrm{CTEPH}+\mathrm{EPC}$ group $(P=.58$ and $P=.11$, respectively; Figure E8, $A$ and $B$ ). With regard to pulmonary hemodynamics, the mPAP and the TPR indexed to the body surface area remained significantly lower in the sham group compared with the CTEPH group and the CTEPH+EPC group (mPAP: $15 \mathrm{~mm} \mathrm{Hg}$, IQR, 14.517.5; $26 \mathrm{~mm} \mathrm{Hg}$, IQR, 23-28; and $24 \mathrm{~mm} \mathrm{Hg}$, IQR, 21.531 , respectively; sham vs CTEPH, $P=.008$ and sham vs CTEPH+EPC, $P=.016 ;$ TPR: 211.6 dynes $/ \mathrm{s} / \mathrm{cm}^{-5}$ [IQR, 161.1-289.5], 525.8 dynes $/ \mathrm{s} / \mathrm{cm}^{-5}$ [IQR, 458.1581.4], and 510.9 dynes/s/ $\mathrm{cm}^{-5}$ [IQR, 451.7-672.1], respectively; sham vs. CTEPH, $P=.004$ and sham vs $\mathrm{CTEPH}+\mathrm{EPC}, P=.007)$. These hemodynamic parameters did not differ significantly between the CTEPH group and CTEPH+EPC group (for mPAP: $P=.90$ and for TPR: 
TABLE 1. Hemodynamic and echocardiographic measurements of the sham, CTEPH, and CTEPH + EPC groups at 10 weeks

\begin{tabular}{lccr}
\hline & Sham group $(\mathbf{n}=\mathbf{5})$ & CTEPH group $(\mathbf{n}=\mathbf{6})$ & CTEPH+EPC group $(\mathbf{n}=\mathbf{5})$ \\
\hline Body weight $(\mathrm{kg})$ & $39.3(37.8-43.65)$ & $34.4(32.25-34.85)$ & $28(26.20-34.60)$ \\
Body surface area & $1.11(1.08-1.20)$ & $1(0.97-1.01)$ & $0.89(0.85-1.01)$ \\
Right heart catheterization & & & \\
$\quad \mathrm{mPAP}, \mathrm{mm} \mathrm{Hg}$ & $15(14.5-17.5)$ & $26(23-28)$ & $24(21.5-31)$ \\
TPR, dyn/s/cm ${ }^{-5}$ & $211.6(161.1-289.5)$ & $525.8(458.1-581.4)$ & $510.9(451.7-672.1)$ \\
$\quad$ Cardiac output indexed & $5.53(4.97-5.75)$ & $3.98(3.65-4.43)$ & $4.12(3.83-4.94)$ \\
Echocardiography & & $32.7(29.5-36.5)$ & $39(37.25-46.5)$ \\
$\quad$ RVFAC, \% & $43.5(33.75-45.48)$ & $15.5(13.75-17.25)$ & $16(15.5-17)$ \\
TAPSE, mm & $21(19.5-21)$ & $19.5(15.5-27.25)$ & $24(23.5-29)$ \\
$\quad$ RV free wall strain, \% & $33(28.6-36)$ & & $0.88(0.67-1.20)$ \\
Conductance measurements & & $0.69(0.56-0.83)$ & \\
$\quad$ Ees/Ea ratio & $1.03(0.92-1.05)$ & & \\
\hline
\end{tabular}

Data are presented as median (IQR). CTEPH, Chronic thromboembolic pulmonary hypertension; $C T E P H+E P C$, chronic thromboembolic pulmonary hypertension and endothelial progenitor cell infusion; $m P A P$, mean pulmonary artery pressure; TPR, total pulmonary resistance; RVFAC, right ventricular fractional area change; TAPSE, tricuspid annular plane systolic excursion; $R V$, right ventricle; Ees/Ea, end-systolic elastance/arterial elastance.

$P=.77$; Figure $3, B$ and $C)$. Last, the Ees/Ea ratio was significantly reduced in the CTEPH group $(0.69$; IQR, 0.56-0.83) compared with the sham group (1.03; IQR, $0.92-1.05 ; P=.008)$. The absence of a significant difference between the sham and the CTEPH+EPC group (0.88; IQR, 0.67-1.20) for the Ees/Ea ratio was indicative of a tendency for improved ventriculoarterial coupling after EPC administration (Figure 3,D). The right ventricular stroke work indexed did not differ between the 3 groups (sham, 685 [IQR, 596.1-932.6], CTEPH, 1202 [IQR, 967.8-1370], and CTEPH+EPC, 868.2 [IQR, 841.21316]; Figure 3, E). Hemodynamic and echocardiography data are summarized in Table 1.

\section{RV and Lung Morphometry}

The PA media thickness in the RUL was greater in the CTEPH group (59.9\%; IQR, 53.3-64.6) and the CTEPH+EPC group (62.4\%; IQR, 54-71.3) compared with the sham group $(25.3 \%$; IQR, 22-27.6; and CTEPH vs sham, $P<.0001$; CTEPH + EPC vs sham, $P<.0001)$, whereas there was no significant difference between the CTEPH animals and the CTEPH + EPC animals $(P=.44$; Figure $4, A-D)$. The cardiomyocyte surface area was higher in the CTEPH group (298.3 $\mu \mathrm{m}^{2}$; IQR, 277.4-335.3) compared with the sham group $\left(212.5 \mu \mathrm{m}^{2}\right.$; IQR, 196.8$260.1 ; P=.008)$. Interestingly, the cardiomyocyte surface area was lower in the CTEPH+EPC group $\left(234.6 \mu \mathrm{m}^{2}\right.$; IQR, 211.1-264.7) compared with the CTEPH group (298.3 $\mu \mathrm{m}^{2}$; IQR, 277.4-335.3; $\left.P=.017\right)$. There was no difference between the sham group and the CTEPH+EPC group $(P=.66$; Figure $4, F, H, I$, and $J)$. Cardiomyocyte hypertrophy was also evaluated according to the $\alpha / \beta$ myosin heavy chain (MHC) ratio. This ratio was significantly lower in the CTEPH group (0.71; IQR, 0.49-1.06) compared with the sham group (2.6; IQR, 1.87-5.25; $P=.004)$. However, the $\alpha / \beta$ MHC ratio was not different after EPC administration (CTEPH+EPC, 3.90; IQR, 0.58-7.21; and CTEPH versus CTEPH+EPC, $P=.18$; Figure $4, F$ ). No EPCs could be detected in the right ventricle at T10, whether using histological assessment (data not shown), analysis of GFP expression using Western blot analysis (Figure E9), or real-time quantitative polymerase chain reaction. However, some EPCs were found in the RUL (Figure $4, K$ ) and in the spleen (Figure 4, $L$ ).

\section{RV Capillary Density}

CD31 immunohistochemical analysis revealed a higher capillary density (capillary per millimeter squared) in the CTEPH group (183.5; IQR, 150.1-215.7) and CTEPH+EPC group (210.6; IQR, 190.8-228.4) compared with the sham group (133.9 [IQR, 125.2-137.9]; CTEPH vs sham, $P<.0001$ and CTEPH+EPC vs sham, $P<.0001)$. There was a trend toward a higher capillary density in the CTEPH+EPC group compared with the CTEPH group $(P=.06)$. CD31 protein quantification revealed increased CD31 expression (CD31/GAPDH expression) in the CTEPH+EPC group (7.14; IQR, 5.56-8.41) compared with the sham group (1.256; IQR, 0.81-1.88; $P=.008)$ and the CTEPH group (3.12; IQR, 1.27-5.08; $P=.017$; Figure $5, A-E)$. The expression of vascular endothelial growth factor (VEGF)-A protein was markedly increased (VEGF-A/GAPDH expression) in the CTEPH group (0.22; IQR, 0.21-0.27) and the CTEPH+EPC group (0.29; IQR, 0.24-0.33) compared with the sham group (0.14 [IQR, 0.18-0.17]; CTEPH vs sham, $P=.004$; $\mathrm{CTEPH}+\mathrm{EPC}$ vs sham, $P=.008$; Figure $5, F)$.

\section{DISCUSSION}

Autologous intracoronary injection of EPCs was associated with an improvement in RV systolic function in an animal model of CTEPH. A reduced cardiomyocyte surface area and a tendency for increased capillary density after 
- Sham

- CTEPH

$\triangle \mathrm{CTEPH}+\mathrm{EPC}$
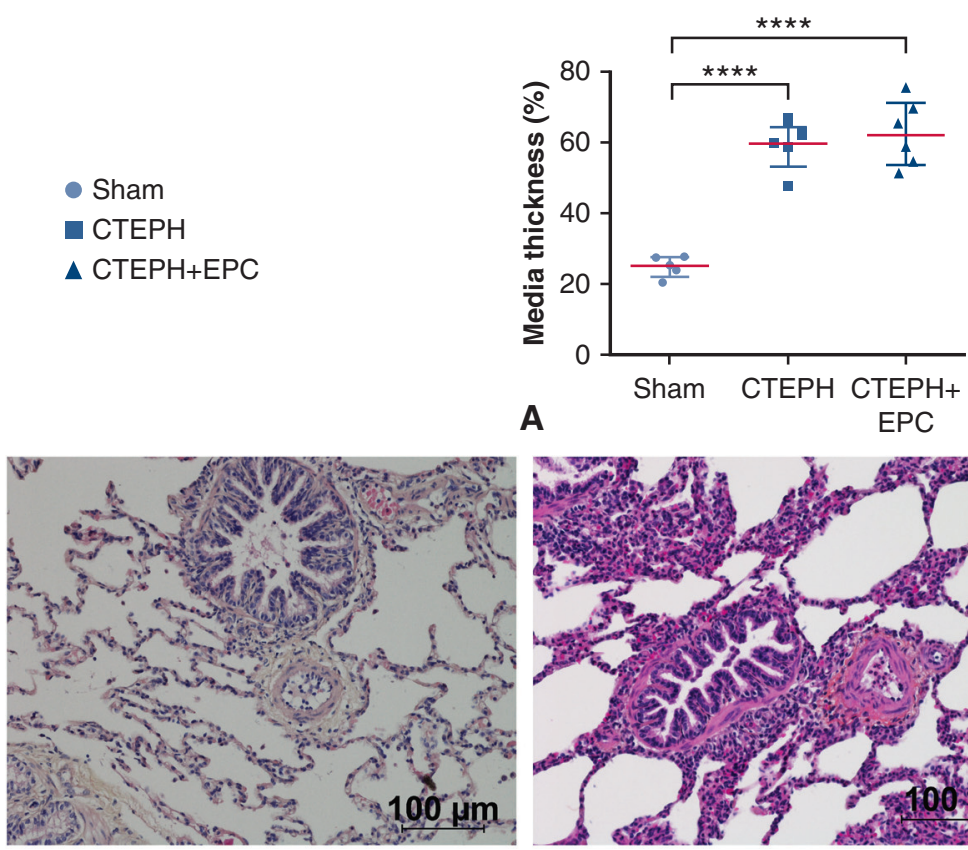

B

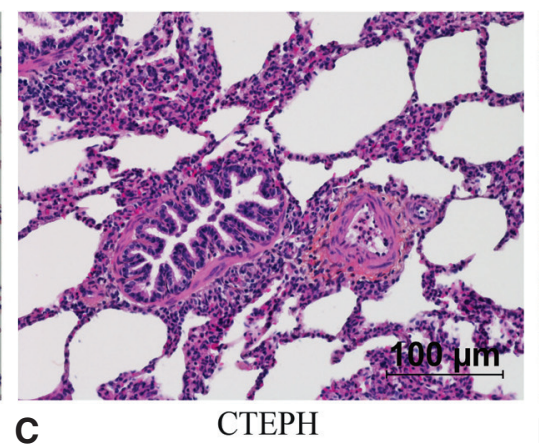

$\mathrm{CTEPH}$

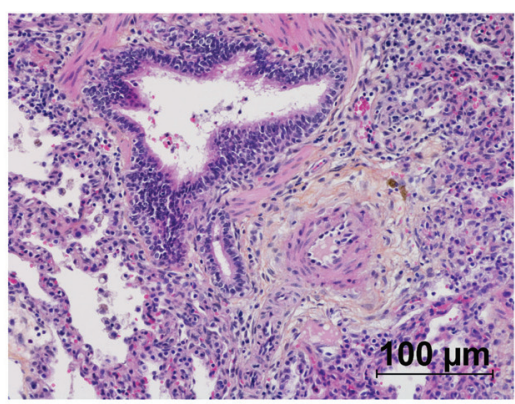

$\mathrm{CTEPH}+\mathrm{EPC}$
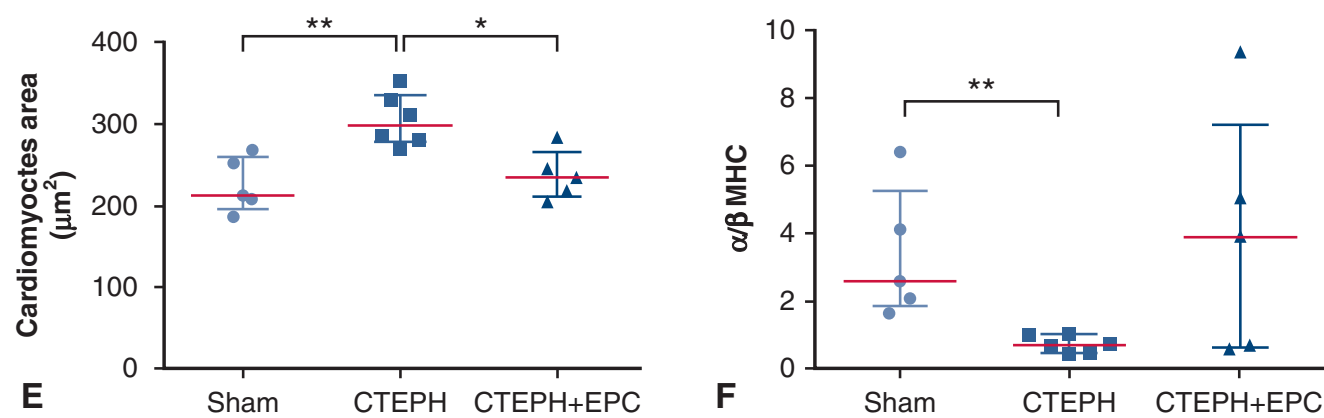

Sham

CTEPH
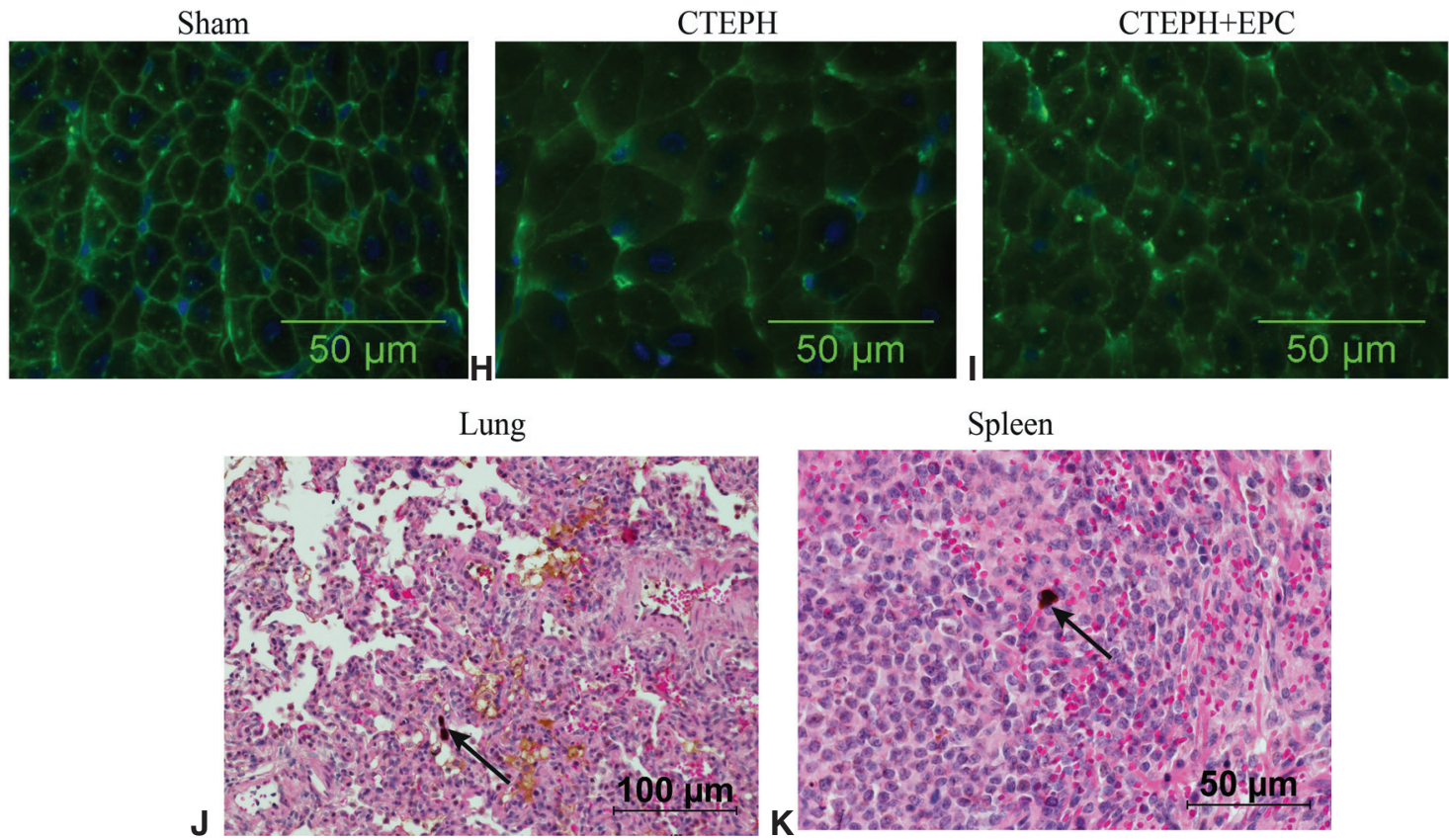
$\mathrm{T} 10$

A

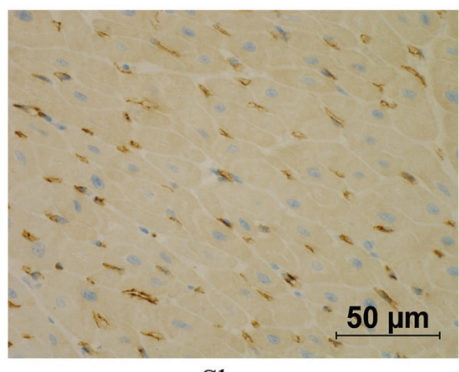

Sham

- Sham

- CTEPH

$\triangle \mathrm{CTEPH}+\mathrm{EPC}$

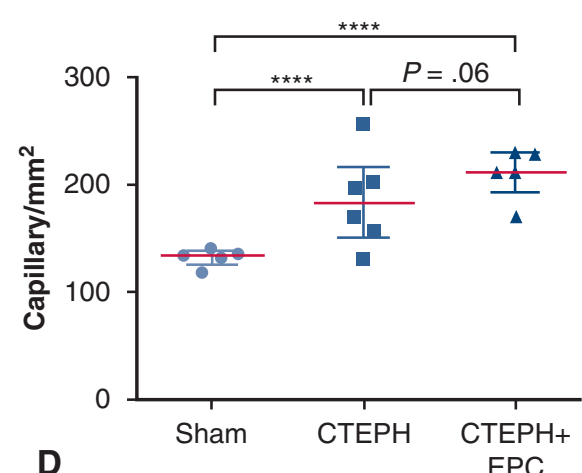

B

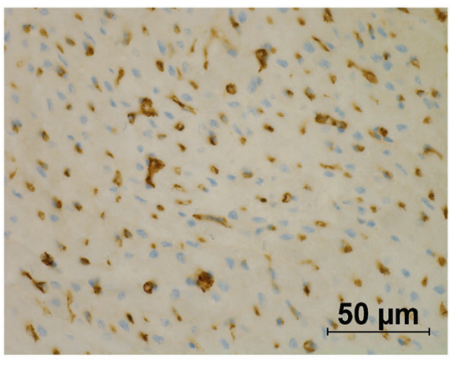

CTEPH

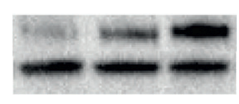

CD31 $130 \mathrm{kDa}$

GAPDH $35 \mathrm{kDa}$

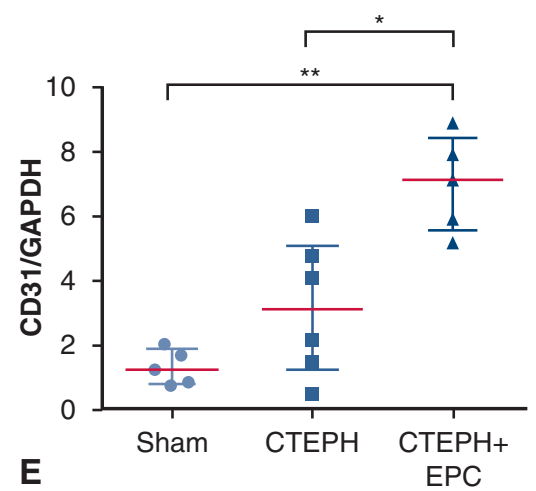

FIGURE 5. Capillary density in the right ventricle at T10. The capillary density quantification was calculated on the basis of immunostaining by $\mathrm{CD} 31$ antibody $(\mathrm{A}, \mathrm{B}$, and $\mathrm{C})$. The capillary density was significantly higher in the chronic thromboembolic pulmonary hypertension $(C T E P H)$ group and the chronic thromboembolic pulmonary hypertension and endothelial progenitor cell infusion $(C T E P H+E P C)$ group compared with the sham group. Immunostaining by CD31 antibody revealed a tendency for increased capillary density in the CTEPH+EPC group compared with the CTEPH group (D), and this was confirmed in CD31 protein quantification (E). VEGF-A protein quantification revealed its increased expression in the CTEPH group and the $\mathrm{CTEPH}+\mathrm{EPC}$ group compared with the sham group $(\mathrm{F}) .{ }^{*} P<.05, * * P<.01$, ****P<.0001. VEGF-A, Vascular endothelial growth factor A; GAPDH, glyceraldehyde-3-phosphate dehydrogenase.

EPC administration were also observed. EPCs were present in the RV and RUL at 4 and 24 hours after their injection in a sham and a CTEPH piglet, respectively. However, at 4 weeks they were only discernible in the RUL and spleen. No differences were observed between the CTEPH and the $\mathrm{CTEPH}+\mathrm{EPC}$ piglets in terms of MPAP and TPR, as well as PA remodeling. Although the mechanistic evidence is limited, our results suggest that EPCs might exert their effect mainly on the right ventricle. Indeed, our results are consistent with a primary effect of EPCs on the right ventricle on the basis of improvement of the RVFAC and the prevention of hypertrophy in the CTEPH+EPC group. We hypothesize that when EPCs are injected intracoronarily they pass through the right ventricle for at least the first 24 hours, during which they might secrete paracrine factors leading to a decrease in the cardiomyocyte surface area and a minor increase in capillary density that results in an improvement of the RV hemodynamic function. It should be noted that these are hypotheses; further studies are required to test these assumptions.

Intracoronary administration of stem cells has been shown to be safe and feasible. ${ }^{20}$ Promising results have

FIGURE 4. Morphometric analysis of the lung and the right ventricle $(R V)$. Measurement of the artery median thickness in the right upper lobe revealed an increase for the chronic thromboembolic pulmonary hypertension $(C T E P H)$ group and the chronic thromboembolic pulmonary hypertension and endothelial progenitor cell infusion $(C T E P H+E P C)$ group compared with the sham group, whereas endothelial progenitor cell (EPC) injection did not lead to any change in the median artery thickness (A, B, C, and D). The cardiomyocyte study revealed a reduced cardiomyocyte surface area (E), confirmed by an increase in the $\alpha / \beta$ myosin heavy chain ratio (F) in the CTEPH+EPC group compared with the CTEPH group. Wheat germ agglutinin cardiomyocyte surface staining in sham (G), CTEPH (H), and CTEPH+EPC (I) animals. GFP-labeled EPCs were not detectable in the RV 4 weeks after their injection, although some were found in the right upper lobe $(\mathrm{J})$ and the spleen $(\mathrm{K})$. Arrows in these panels show the presence of EPC. *P<.05, **P<.01, ****P<.0001. GFP, Green fluorescent protein. 
been obtained in terms of improvement of left ventricular function in patients with heart failure such as myocardial infarction $^{21}$ and dilated cardiomyopathy, ${ }^{22}$ although in some cases the true effectiveness of the cell therapy is debatable. Using a porcine model of CTEPH, we showed that intracoronary administration of EPCs is safe and feasible (eg, no arrhythmia, myocardial infarction, or sudden death after the procedure). In keeping with previous studies that used an intracoronary delivery route, ${ }^{23}$ there was low cell retention at 4 weeks. The observed absence of EPCs was not because of a lack of GFP expression over time because GFP was transmitted to the daughter cells after cell division. Low cell retention is one of the major drawbacks of intracoronary administration as a result, in this case, it might not be the optimal route of administration.

To our knowledge we are the first to administer EPCs directly into the right ventricle of a $\mathrm{PH}$ model. ${ }^{24}$ To date, most of the other EPC therapy studies targeting PH cannot readily be compared with ours because they used the monocrotaline-induced PH rat model. With this model, there is targeting of the pulmonary circulation rather than $\mathrm{RV}$ function using intravenous EPC administration. The effects on the right ventricle were indirect, because pronounced pulmonary effects such as reduced pulmonary arteriole muscularization, reduced pulmonary vessel wall thickening, and an increased number of lung small arterioles were also observed. ${ }^{25,26}$ In contrast, in our study, intracoronary EPC administration improved RV function independently of a decrease in the RV afterload.

After intracoronary administration of EPCs, a decrease in the cardiomyocyte area was observed. $\mathrm{Gu}$ and colleagues showed that EPC-derived microvesicles were able to prevent angiotensin II-induced cardiomyocyte hypertrophy in vitro. ${ }^{27}$ The reduced cardiomyocyte area and the tendency to a decreased $\alpha / \beta$ MHC ratio observed after EPC injection suggests that these cells reversed the RV remodeling. RV reverse remodeling has already been reported in $\mathrm{PH}$ patients after lung transplantation, ${ }^{28}$ pulmonary endarterectomy, ${ }^{29}$ and balloon pulmonary angioplasty. ${ }^{30}$ In this study, RV hypertrophy seemed to be prevented by stem cell therapy. Ventricular hypertrophy could be deleterious in case of myocardial ischemia. Indeed, ventricular hypertrophy, combined with increased afterload and increased wall stress, has been shown to lead to increased myocardial oxygen demand and, as a result, myocardial ischemia. ${ }^{31}$ In this study, the stem cell therapy used might have reversed cardiac remodeling of the right ventricle.

EPCs can participate directly in revascularization by repairing damaged vessels or by forming neovessels. Their role in the induction of angiogenesis through direct integration into vessels has been shown using murine models of ischemia. ${ }^{10-12}$ EPCs administered into myocardial infarcted rats have been shown to secrete paracrine factors that lead to a favorable cardiac remodeling. ${ }^{9,32}$ Because there is poor cell retention, the effects that we observed were likely due to paracrine secretion by the EPCs. fibroblast growth factor-2, IGF-1, and stromal cell-derived factor- $1 \alpha$ are paracrine factors for which levels were increased in ischemic heart after EPC transplantation. ${ }^{9}$ Furthermore, a positive effect after EPC administration on left ventricle post myocardial infarction was found to be mediated by IGF- $1 .^{32}$ Surprisingly, the level of VEGF was upregulated despite a lack of an effect on capillary growth. There might be 2 explanations for this increase in the level of VEGF: (1) EPCs might give rise to a self-sustaining angiogenic microenvironment at the time of RV injection; and (2) the capillary density might not have reached a sufficient level to cover RV needs despite the increase in VEGF expression. Although we have few mechanistic data, we speculate that the observed effect could be a result of one of these paracrine factors.

Although RV function determines PH patient survival, when the afterload of the right ventricle is alleviated by pulmonary endarterectomy or lung transplantation, the right ventricle has the ability to remodel and return to normal within weeks or months. ${ }^{28,33}$ Only targeting the right ventricle would hence provide little benefit, because the pulmonary vasculature would still be obstructed and the right ventricle would therefore still be subject to a high afterload. Because the stem cell therapy that we developed only targets the right ventricle, we aim to use this therapy in combination with current therapies targeting the pulmonary vasculature. The additional targeting of the right ventricle with our EPC-based therapy might prolong the survival of patients.

\section{Limitations}

One major limitations of our experimental CTEPH model is the lack of a decrease in the capillary density in the right ventricle. We sacrificed the animals at 4 weeks after the establishment of PH, as opposed to Noly and colleagues, ${ }^{17}$ who studied the same model after 14 weeks, at which time they found a decrease in the capillary density. To overcome the absence of reduced capillary density, a different model could be investigated so as to evaluate the effect of EPCs in the right ventricle without having the pulmonary component. Alternatively, the time of EPC administration could be delayed to obtain a higher level of RV dysfunction, thus leading to the capillary rarefaction, as observed by Noly and colleagues. ${ }^{17}$ Finally, heterogeneity of the disease between piglets at $\mathrm{T} 6$ makes it difficult to observe significant effects of therapy. However, because the model is stable over the time, ${ }^{17}$ we are confident that the disease phenotype is not temporary.

Although we showed differences between groups considering RVFAC evaluation, we only found a significant difference between CTEPH with and without EPCs. The lack of 
power of the study, the low severity of the modeled disease, and the early post injection evaluation might explain these results. However, despite this animal model-induced limitations, we found that RV function was significantly improved after EPC injection in CTEPH animals.

In this study, peripheral blood collection was only performed in the CTEPH+EPC pigs. Because blood collected was less than $7.5 \%$ of the piglets' blood volume the recovery period lasted $<1$ week. ${ }^{34}$ We assume that it did not affect our comparative results.

Despite EPC availability in peripheral blood of PH patients, ${ }^{35}$ the main concerns regarding the translation of this cell therapy to clinical studies is the use of autologous cells. First, it could be particularly taxing for severe PH patients to provide a significant blood sample to isolate EPCs. Second, the timing between blood sampling, EPC isolation and proliferation, and EPC administration needs to be fully optimized. One solution could be to collect blood after diagnosis of the disease, then to isolate and freeze the EPCs and wait for the patient to be ready for their administration. Third, EPCs isolated from patients with $\mathrm{PH}$ might have altered functionality ${ }^{36}$ and would require an assessment before use. EPCs isolated from cord blood could be an alternative to autologous EPCs for overcoming all of these limitations. Several studies have shown the superiority of cord blood EPCs over adult EPCs in terms of their proliferative capacity and their ability to create new vessels and to participate in angiogenesis, and their use has already been proposed for several clinical applications. ${ }^{37-39}$

\section{CONCLUSIONS}

Using a porcine model of CTEPH, right intracoronary EPC administration seemed to have a positive effect on $\mathrm{RV}$ adaptation to PH. Further studies are needed to determine the best way for administering EPCs, and to confirm these encouraging results in other types of $\mathrm{PH}$ models. EPC therapy appears to be a promising therapy to sustain $\mathrm{RV}$ function in PH. When used in combination with pulmonary circulation-targeted therapies, this new therapy has the potential to provide clinical benefits for $\mathrm{PH}$ patients.

\section{Conflict of Interest Statement}

Authors have nothing to disclose with regard to commercial support.

\section{References}

1. Ghio S, Gavazzi A, Campana C, Inserra C, Klersy C, Sebastiani R, et al. Independent and additive prognostic value of right ventricular systolic function and pulmonary artery pressure in patients with chronic heart failure. J Am Coll Cardiol. 2001;37:183-8.

2. Ryan JJ, Archer SL. Emerging concepts in the molecular basis of pulmonary arterial hypertension: part I: metabolic plasticity and mitochondrial dynamics in the pulmonary circulation and right ventricle in pulmonary arterial hypertension. Circulation. 2015;131:1691-702.
3. Ryan JJ, Archer SL. The right ventricle in pulmonary arterial hypertension: disorders of metabolism, angiogenesis and adrenergic signaling in right ventricular failure. Circ Res. 2014;115:176-88.

4. Sutendra G, Dromparis P, Paulin R, Zervopoulos S, Haromy A, Nagendran J, et al. A metabolic remodeling in right ventricular hypertrophy is associated with decreased angiogenesis and a transition from a compensated to a decompensated state in pulmonary hypertension. J Mol Med Berl Ger. 2013;91:1315-27.

5. Bogaard HJ, Natarajan R, Henderson SC, Long CS, Kraskauskas D, Smithson L, et al. Chronic pulmonary artery pressure elevation is insufficient to explain right heart failure. Circulation. 2009;120:1951-60.

6. Ruiter G, Ying Wong Y, de Man FS, Louis Handoko M, Jaspers RT, Postmus PE, et al. Right ventricular oxygen supply parameters are decreased in human and experimental pulmonary hypertension. J Heart Lung Transplant. 2013;32: 231-40.

7. Gómez A, Bialostozky D, Zajarias A, Santos E, Palomar A, Martínez ML, et al. Right ventricular ischemia in patients with primary pulmonary hypertension. $J$ Am Coll Cardiol. 2001;38:1137-42.

8. Boyer-Di Ponio J, El-Ayoubi F, Glacial F, Ganeshamoorthy K, Driancourt C, Godet M, et al. Instruction of circulating endothelial progenitors in vitro towards specialized blood-brain barrier and arterial phenotypes. PLoS One. 2014;9: e84179.

9. Kim SW, Jin HL, Kang SM, Kim S, Yoo KJ, Jang Y, et al. Therapeutic effects of late outgrowth endothelial progenitor cells or mesenchymal stem cells derived from human umbilical cord blood on infarct repair. Int J Cardiol. 2016;203: 498-507.

10. Murohara T, Ikeda H, Duan J, Shintani S, Sasaki K, Eguchi H, et al. Transplanted cord blood-derived endothelial precursor cells augment postnatal neovascularization. J Clin Invest. 2000;105:1527-36.

11. Flex A, Biscetti F, Iachininoto MG, Nuzzolo ER, Orlando N, Capodimonti S, et al. Human cord blood endothelial progenitors promote post-ischemic angiogenesis in immunocompetent mouse model. Thromb Res. 2016;141:106-11.

12. Peng XG, Bai Y, James JR, Shlapak DP, Ju S. Transplanted endothelial progenitor cells improve ischemia muscle regeneration in mice by diffusion tensor MR imaging. Stem Cells Int. 2016;2016:3641401.

13. Simonneau G, Gatzoulis MA, Adatia I, Celermajer D, Denton C, Ghofrani A, et al. Updated clinical classification of pulmonary hypertension. J Am Coll Cardiol. 2013;62(25 Suppl):D34-41.

14. Mercier O, Tivane A, Dorfmüller P, de Perrot M, Raoux F, Decante B, et al. Piglet model of chronic pulmonary hypertension. Pulm Circ. 2013;3:908-15.

15. Noly PE, Guihaire J, Coblence M, Dorfmüller P, Fadel E, Mercier O. Chronic thromboembolic pulmonary hypertension and assessment of right ventricular function in the piglet. $J$ Vis Exp. 2015; 53133.

16. Guihaire J, Haddad F, Boulate D, Capderou A, Decante B, Flécher E, et al. Right ventricular plasticity in a porcine model of chronic pressure overload. J Heart Lung Transplant. 2014;33:194-202.

17. Noly PE, Haddad F, Ataam JA, Langer N, Dorfmüller P, Loisel F, et al. The importance of capillary density/stroke work mismatch for right ventricular adaptation to chronic pressure overload. J Thorac Cardiovasc Surg. 2017;154:2070-9.

18. Vonk Noordegraaf A, Haddad F, Bogaard HJ, Hassoun PM. Noninvasive imaging in the assessment of the cardiopulmonary vascular unit. Circulation. 2015;131: 899-913.

19. Bensley JG, De Matteo R, Harding R, Black MJ. Three-dimensional direct measurement of cardiomyocyte volume, nuclearity, and ploidy in thick histological sections. Sci Rep. 2016;6:23756.

20. Vrtovec B, Poglajen G, Lezaic L, Sever M, Socan A, Domanovic D, et al. Comparison of transendocardial and intracoronary CD34+ cell transplantation in patients with nonischemic dilated cardiomyopathy. Circulation. 2013;128(11 Suppl 1) S42-9.

21. Chugh AR, Beache GM, Loughran JH, Mewton N, Elmore JB, Kajstura J, et al Administration of cardiac stem cells in patients with ischemic cardiomyopathy: the SCIPIO trial: surgical aspects and interim analysis of myocardial function and viability by magnetic resonance. Circulation. 2012;126(11 Suppl 1): S54-64.

22. Lezaic L, Socan A, Poglajen G, Peitl PK, Sever M, Cukjati M, et al. Intracoronary transplantation of CD34 $(+)$ cells is associated with improved myocardial perfusion in patients with nonischemic dilated cardiomyopathy. J Card Fail. 2015;21:145-52.

23. Li X, Tamama K, Xie X, Guan J. Improving cell engraftment in cardiac stem cell therapy. Stem Cells Int. 2016;2016:7168797.

24. Loisel F, Provost B, Haddad F, Guihaire J, Amsallem M, Vrtovec B, et al. Stem cell therapy targeting the right ventricle in pulmonary arterial hypertension: is it a potential avenue of therapy? Pulm Circ. 2018;8. 2045893218755979. 
25. Yip HK, Chang LT, Sun CK, Sheu JJ, Chiang CH, Youssef AA, et al. Autologous transplantation of bone marrow-derived endothelial progenitor cells attenuates monocrotaline-induced pulmonary arterial hypertension in rats. Crit Care Med. 2008:36:873-80.

26. Xia L, Fu GS, Yang JX, Zhang FR, Wang XX. Endothelial progenitor cells may inhibit apoptosis of pulmonary microvascular endothelial cells: new insights into cell therapy for pulmonary arterial hypertension. Cytotherapy. 2009;11:492-502.

27. Gu S, Zhang W, Chen J, Ma R, Xiao X, Ma X, et al. EPC-derived microvesicles protect cardiomyocytes from Ang II-induced hypertrophy and apoptosis. PLoS One. 2014;9:e85396.

28. Sarashina T, Nakamura K, Akagi S, Oto T, Oe H, Ejiri K, et al. Reverse right ventricular remodeling after lung transplantation in patients with pulmonary arterial hypertension under combination therapy of targeted medical drugs. Circ J. 2017; $81: 383-90$

29. Berman M, Gopalan D, Sharples L, Screaton N, Maccan C, Sheares K, et al. Right ventricular reverse remodeling after pulmonary endarterectomy: magnetic resonance imaging and clinical and right heart catheterization assessment. Pulm Circ. 2014;4:36-44.

30. Fukui S, Ogo T, Morita Y, Tsuji A, Tateishi E, Ozaki K, et al. Right ventricular reverse remodelling after balloon pulmonary angioplasty. Eur Respir J. 2014;43: 1394-402.

31. Stanton T, Dunn FG. Hypertension, left ventricular hypertrophy, and myocardial ischemia. Med Clin North Am. 2017;101:29-41.

32. Hynes B, Kumar AH, O'Sullivan J, Klein Buneker C, Leblond AL, Weiss S, et al. Potent endothelial progenitor cell-conditioned media-related anti-apoptotic, cardiotrophic, and pro-angiogenic effects post-myocardial infarction are mediated by insulin-like growth factor-1. Eur Heart J. 2013;34:782-9.
33. Reesink HJ, Marcus JT, Tulevski II, Jamieson S, Kloek JJ, Vonk Noordegraaf A et al. Reverse right ventricular remodeling after pulmonary endarterectomy in patients with chronic thromboembolic pulmonary hypertension: utility of magnetic resonance imaging to demonstrate restoration of the right ventricle. $J$ Thorac Cardiovasc Surg. 2007;133:58-64.

34. Diehl KH, Hull R, Morton D, Pfister R, Rabemampianina Y, Smith D, et al. A good practice guide to the administration of substances and removal of blood, including routes and volumes. J Appl Toxicol. 2001;21:15-23.

35. Smadja DM, Mauge L, Sanchez O, Silvestre JS, Guerin C, Godier A, et al. Distinct patterns of circulating endothelial cells in pulmonary hypertension. Eur Respir J. 2010;36:1284-93.

36. Grisar JC, Haddad F, Gomari FA, Wu JC. Endothelial progenitor cells in cardiovascular disease and chronic inflammation: from biomarker to therapeutic agent. Biomark Med. 2011;5:731-44.

37. Au P, Daheron LM, Duda DG, Cohen KS, Tyrrell JA, Lanning RM, et al. Differential in vivo potential of endothelial progenitor cells from human umbilical cord blood and adult peripheral blood to form functional long-lasting vessels. Blood. 2008;111:1302-5.

38. Janic B, Arbab AS. Cord blood endothelial progenitor cells as therapeutic and imaging probes. Imaging Med. 2012;4:477-90.

39. Kim J, Jeon YJ, Kim HE, Shin JM, Chung HM, Chae JI. Comparative proteomic analysis of endothelial cells progenitor cells derived from cord blood and peripheral blood for cell therapy. Biomaterials. 2013;34:1669-85.

Key Words: pulmonary hypertension, right ventricle, stem cell therapy, endothelial progenitor cells 


\section{APPENDIX 1. SUPPLEMENTAL METHODS Chronic Thromboembolic Piglet Model}

Three of the CTEPH piglets died as a result of an acute right heart failure after embolization. Another animal was withdrawn from the study because of bacterial contamination of the cultured EPCs. Because this event occurred after 2 weeks of cell culture, the animal was withdrawn from the study. There were no deaths related to infection of the surgical site. A sham animal died 2 weeks after being included in the study, independently of the experimental procedures. There were no deaths in the CTEPH+EPC group after EPC administration (T6), nor were there any in the CTEPH group after saline administration (T6). Cardiac troponin I levels were measured just before EPC administration and at 1, 4, and 24 hours, and 4 weeks later using Dimension Vista (Siemens, Newark, NJ).

All of the animals received humane husbandry and care, and they were housed at the Marie Lannelongue animal facilities under conditions that complied with the Principles of Laboratory Animal Care formulated by the National Society for Medical Research and the Guide for the Care and Use of Laboratory Animals prepared by the Institute of Laboratory Animal Resources and published by the National Institutes of Health (NIH Publication 86-23, revised in 1996) and the guidelines from Directive 2010/63/EU of the European Parliament on the protection of animals used for scientific purposes (APAFIS 7649-2016-112114519868v1).

\section{EPC Harvesting}

Peripheral blood samples of $100 \mathrm{~mL}$ were only collected from the CTEPH+EPC piglets at 3 weeks to isolate EPCs. An autologous cellbased therapy was established because the treated piglets received EPCs isolated 3 weeks previously from their own blood. EPCs were harvested using isolation of peripheral blood mononuclear cells using gradient centrifugation in Pancoll (Dutsher, Burmath, France), after which they were plated at a density of $50,000 \mathrm{cells} / \mathrm{cm}^{2}{ }^{\text {E1 }}$ The peripheral blood mononuclear cells were maintained in endothelial basal medium-2 supplemented with EGM2MV Single-Quots (containing human endothelial growth factor, hydrocortisone, gentamicin, fetal bovine serum, VEGF, human fibroblast growth factor-B, $\mathrm{R}^{3}$-IGF-1, and ascorbic acid; Lonza, Ermerainville, France) at $37^{\circ} \mathrm{C}$ in a $5 \% \mathrm{CO}_{2}$ humidified incubator. After 8 to 15 days, cell colonies became visible and they were detached using trypsinization, followed by seeding at 10,000 cells $/ \mathrm{cm}^{2}$ for expansion. The EPCs were characterized by fluorescence-activated cell sorting analysis (Figure E1, A). The cells were detached using trypsinization and resuspended in phosphatebuffered saline (PBS) containing 5\% bovine serum albumin. Separate stainings were performed for 30 minutes with each of the following antibodies: anti-CD31 (PECAM-1 at 1:100 dilution; Millipore, Burlington, Mass), anti-CD144 (Ve-Cadherin at 1:10 dilution; Santa Cruz Biotechnology, Dallas, Tex), and anti-VEGF receptor-2 at 1:20 dilution; Millipore). To detect these markers, the cells were stained with fluorescent secondary antibodies: goat anti-mouse Alexa Fluor 488 or donkey antigoat Alexa Fluor 546 (Invitrogen). Fluorescence-activated cell sorting analysis was performed with a BD Accuri C6 Plus platform (BD Bioscience, Franklin Lakes, NJ) and the flow data were analyzed with BD Accuri C6 software (BD Bioscience). All of the administered EPCs were transduced with a lentivirus expressing GFP (Vectalys; Canal Biotech II, Toulouse, France) and they were detected with an anti-GFP antibody (GFP 2555 at 1:400 dilution, Cell Signaling Technology, Danvers, Mass) visualized using ultraView Universal DAB Detection Kit (Ventana) staining with Benchmark GX (Roche). To ensure a pure EPC fraction, in addition to being characterized by their expression markers, the EPCs were also assessed for their ability to internalize Ac-LDL. Briefly, EPCs were incubated with $15 \mu \mathrm{g} / \mathrm{mL}$ of Ac-LDL AlexaFluor 488 (Invitrogen) for 4 hours at $37^{\circ} \mathrm{C}$. After washes with $\mathrm{PBS}$, the cells were fixed with $4 \%$ paraformaldehyde (PFA). The fluorescent cells were observed using a Leica DMR fluorescence microscope (Wetzlar, Germany) (Figure E1, B).

\section{EPC Administration}

EPC viability was assessed after saline resuspension, shortly before their administration (Figure E2). Briefly, a fluorescent viability staining solution (7AAD) was added to EPCs resuspended in saline solution, and the fluorescence was analyzed using flow cytometry. EPCs resuspended in culture medium and permeabilized EPCs served as controls.

\section{Tissue Harvesting}

At T10, random biopsies of the RUL were fixed with 4\% PFA, processed using standard histology techniques, and morphometric measurements were performed to determine the artery media thickness using imaging software (NIS-Elements, Nikon). The PA media thickness of RUL pulmonary arteries (70-250 $\mu \mathrm{m}$ in diameter) was calculated as (external diameter - internal diameter/external diameter) $\times 100$. All of the morphometric studies were performed in a blinded manner. The RV free wall, left ventricle, liver, kidney, and spleen biopsies were snapfrozen in liquid nitrogen and stored at $-80^{\circ} \mathrm{C}$ for molecular biology analyses; or fixed with $4 \%$ PFA solution for histology processing and morphometric measurements.

\section{Real-Time Quantification Using Polymerase Chain Reaction}

RNA was obtained using phenol-chloroform extraction and a gentleMACS Dissociator (Miltenyi Biotec, Bergisch Gladbach, Germany). Reverse transcription was performed using $1 \mu \mathrm{g}$ of RNA with the Quantitect Reverse Transcription Kit (Qiagen, Hilden, Germany) according to the manufacturer's instructions. During fetal development, $\alpha$-MHC replaces $\beta$ MHC as the dominant transcript in the heart. In cardiac hypertrophy, there is a shift from the normally predominant $\alpha$-MHC toward $\beta$-MHC. ${ }^{\mathrm{E} 2}$ In light of this change on hypertrophy, $\alpha$-MHC and $\beta$-MHC expression were quantified with specific TaqMan probes: $\alpha$-MHC (Hs01101447_g1, ThermoFisher Scientific, Mass) and $\beta$-MHC (Ss03392423_m1, ThermoFisher Scientific). Relative quantification was achieved with the comparative $2^{-\Delta \Delta \mathrm{Ct}}$ method by normalization with $18 \mathrm{~S} \mathrm{RNA}$ as the reporter gene.

\section{Western Blot Analysis}

Protein extracts were obtained using a gentleMACS Dissociator (Miltenyi Biotec), resolved on $4 \%$ to $15 \%$ sodium dodecyl sulfate polyacrylamide gels, transferred to nitrocellulose membranes (Bio-Rad, Marnes la Coquette, France), blocked with $5 \%$ bovine serum albumin in tris-buffered saline containing $0.1 \%$ Tween and then incubated with anti-CD31 polyclonal antibody (1:250, purified rabbit anti-human; Abcam 28364; Abcam, Cambridge, United Kingdom) or anti-VEGF-A antibody (1:1,000, purified mouse anti-pig, Novus Biological, Littleton, Colo). After incubation with secondary donkey anti-rabbit antibody (1:500, Santa Cruz sc2313) or donkey anti-mouse (1:2000, Santa Cruz sc2314), immunoreactive bands were detected using chemiluminescence with a Perkin Elmer Kit (ECL Plus; Perkin Elmer, Waltham, Mass) in a Chemidoc (Bio-Rad) instrument. Relative quantification was performed by normalization with GAPDH.

\section{Hemodynamic Assessments}

To assess heart rate, mPAP, and cardiac output, an 8-French introducer (Radiofocus Introducer II; Terumo, Tokyo, Japan) was placed percutaneously in the upper vena cava according to the Seldinger technique. A 7French Swan-Ganz catheter (Edwards Lifesciences, Irvine, Calif) was introduced into the upper vena cava, then into the right heart following the pressure curve of the right atrium and the right ventricle, and finally into the PA. Systolic, diastolic, and mPAP were measured in maximal exhalation under $100 \% \mathrm{FiO}_{2}$. The TPR was calculated using the formula: TPR $\left(\mathrm{dyn} / \mathrm{s}^{-1} / \mathrm{cm}^{-5}\right)=(\mathrm{mPAP} \times 80) /$ cardiac output. The cardiac output was obtained using the direct thermodilution method (Vigilance Monitor 
VGS2V, Edwards Lifesciences) by injecting $10 \mathrm{~mL}$ of frozen physiological serum (temperature between $1{ }^{\circ} \mathrm{C}$ and $4^{\circ} \mathrm{C}$ ). The average of 3 consecutive measurements was recorded. The values obtained were indexed to the body surface area defined by Kelly's equation: body surface area $\left(\mathrm{cm}^{2}\right)=734 \times$ weight $(\mathrm{kg})^{0656}$.

For pressure-volume loop analysis, an 8-French balloon catheter was inserted percutaneously through the right femoral vein up to the inferior vena cava-right atrium junction under fluoroscopic guidance. During the pressure-volume loop recordings, the balloon was inflated to progressively reduce the RV preload and thus modify the pressure-volume loop aspect. The slope of the end-systolic pressure-volume relationship defined the Ees of the right ventricle. The ratio of RV end-systolic pressure to stroke volume defined the pulmonary Ea, and the Ees/Ea ratio was thus obtained, corresponding to the value of the RV-PA coupling. All of the measurements were repeated 3 times and averaged.

To compare EPCs before and after CTEPH establishment we isolated EPCs from 3 piglets at 2 time points $(n=3$, paired sample):

- First time point: blood samples were collected shortly before the ligation of the left PA, which is the first step of the CTEPH establishment in piglets (T0).

- Second time point: blood samples were collected when CTEPH was established in piglets (T6).

\section{Ac-LDL Uptake}

EPCs were cultured with $15 \mu \mathrm{g} / \mathrm{mL}$ of Ac-LDL Alexa Fluor 488 for 4 hours at $37^{\circ} \mathrm{C}$. Internalization of Ac-LDL was visualized using a fluorescence microscope at $200 \times$ magnification (NIS-Element software; Nikon).

\section{Wound Healing Assay}

For the cellular healing migration assay, 21,000 EPCs were seeded in each part of the culture insert (Ibidi 80241; Martinsried, Germany). When the cells reached confluency, the culture insert was removed, thereby creating a reproducible cell-free gap. The cells were washed with $1 \times$ PBS and then incubated in endothelial growth medium- 2 medium. Filling of the wound area was immediately captured using videomicroscopy (Metamorph software, version $7.7 ; 10 \times$ objective; Olympus, Tokyo, Japan) over a period of 24 hours, during which the cells were incubated at $37^{\circ} \mathrm{C}$ and a $5 \% \mathrm{CO}_{2}$ atmosphere. The cell-free area in the center of the well was imaged every hour and its area was determined using ImageJ software. To search for a statistical difference between the control and the CTEPH EPCs, a linear regression was applied using Prism 6 software (GraphPad).

\section{Carboxyfluorescein Succinimidyl Ester Cell Proliferation}

EPCs were seeded at a density of 5000 cells $/ \mathrm{cm}^{2}$ and they were incubated with $0.5 \mu \mathrm{M}$ carboxyfluorescein succinimidyl ester (Vybrant
CFDA SE Cell Tracer Kit, ThermoFisher Scientific, Mass) for 10 minutes when they had adhered to the culture substrate. Incubation of cells with carboxyfluorescein succinimidyl ester results in covalent labeling of intracellular proteins with a stable dye, and every generation of cells appears as a distinct peak on a flow cytometry histogram. The cells were then washed with $1 \times$ PBS and incubated in medium, except for at time 0 hours, at which the cells were detached using trypsinization and analyzed using a flow cytometer with excitation at $488 \mathrm{~nm}$ and emission filters appropriate for the detection of the fluorescent signal. Cell fluorescence was also assessed at 24,48 , and 72 hours to evaluate cell proliferation over 3 days.

\section{MTS Assay}

The 3-(4,5-dimethylthiazol-2-yl)-5-(3-carboxymethoxyphenyl)-2-(4sulfophenyl)-2H-tetrazolium (MTS) assay is a colorimetric method for determining the number of viable cells in a population; 5000 EPCs were seeded in triplicate in a 96-well plate, and the cells were then incubated with MTS reagent (CellTiter 96 Aqueous Non-Radioactive Cell Proliferation Assay; Promega, Madison, Wis) for 2 hours according to the manufacturer's instructions. The absorbance at $490 \mathrm{~nm}$ was then measured using a ThermoLabSystem Multiskan EX (ThermoFisher Scientific, Mass).

\section{Bromodeoxyuridine Incorporation Assay}

Bromodeoxyuridine (5-bromo-2-deoxyuridine; BrdU) is a synthetic analogue of the nucleoside thymidine and it is used to identify proliferating cells. EPCs were seeded in triplicate in 96-well plates (at 7500 cells per well), and the cells were then incubated with BrdU for 4 hours according to the manufacturer's instructions (BrdU Cell Proliferation Assay Kit 6813, Cell Signaling Technology). After fixation of the cells and incubation with primary and secondary antibodies followed by substrate, the absorbance was measured at $450 \mathrm{~nm}$ using a ThermoLabSystem Multiskan EX (ThermoFisher Scientific, Mass).

\section{Statistical Analysis for the Supplemental Methods}

The control group and the CTEPH group were compared 2 by 2 with the Wilcoxon matched-pairs rank test. The results are presented as median (IQR). $P$ values $<.05$ were considered statistically significant. Statistical analyses were performed using Prism 6 software (GraphPad).

\section{E-References}

E1. Vanneaux V, El-Ayoubi F, Delmau C, Driancourt C, Lecourt S, Grelier A, et al. In vitro and in vivo analysis of endothelial progenitor cells from cryopreserved umbilical cord blood: are we ready for clinical application? Cell Transplant. 2010;19:1143-55.

E2. Machackova J, Barta J, Dhalla NS. Myofibrillar remodeling in cardiac hypertrophy, heart failure and cardiomyopathies. Can J Cardiol. 2006;22:953-68. 

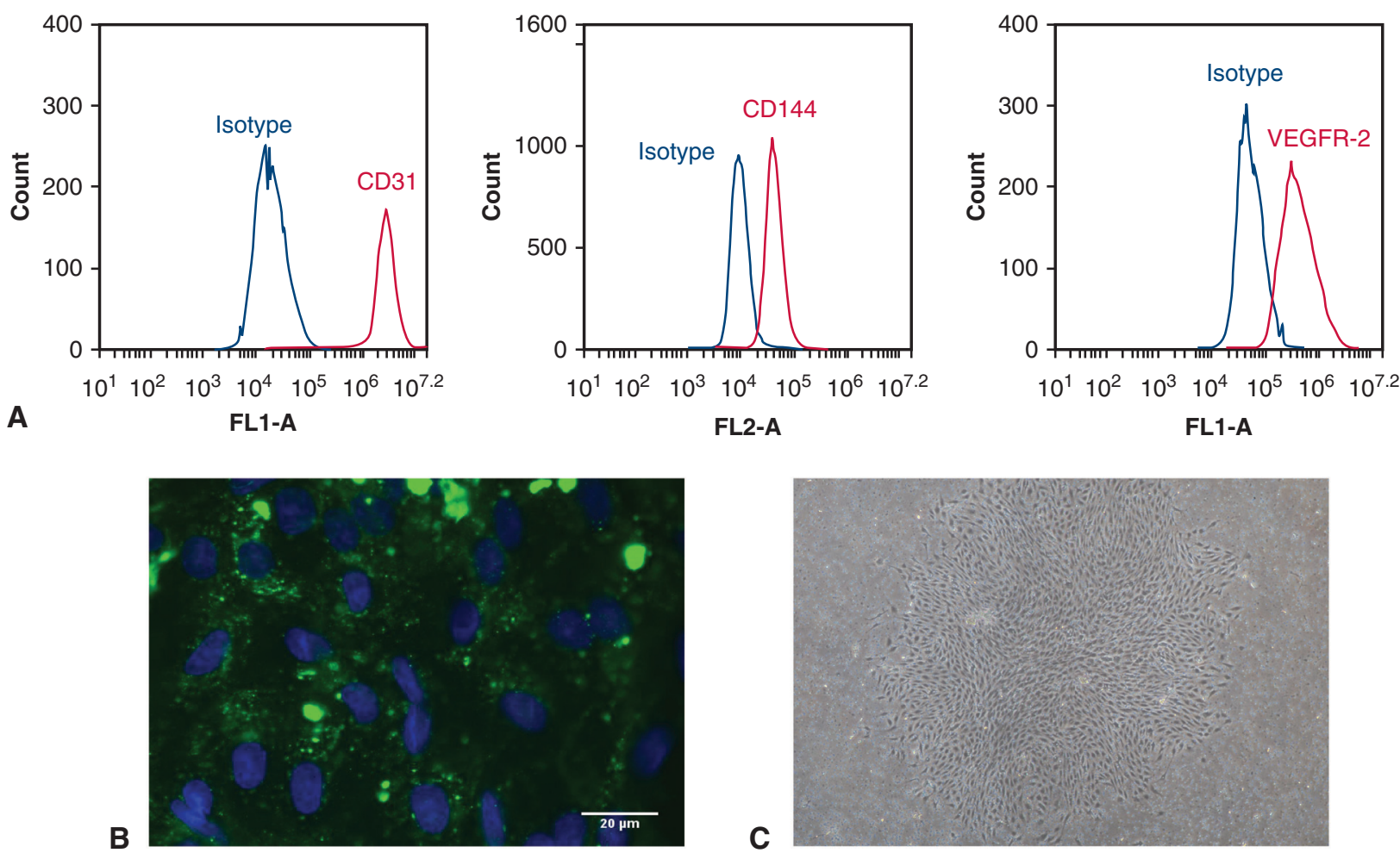

C

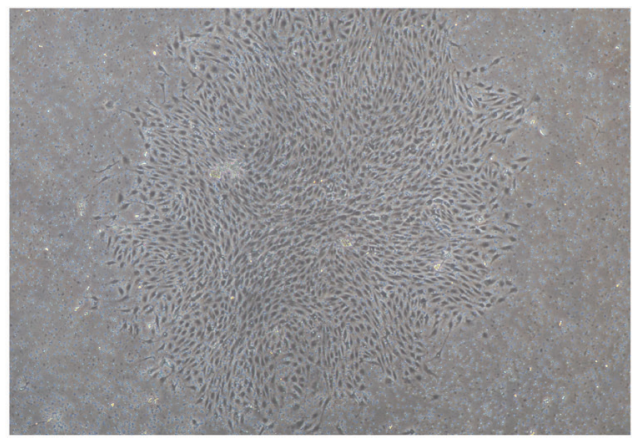

FIGURE E1. Endothelial progenitor cell (EPC) characterization. Analysis of EPC expression markers (CD31, CD144, and VEGFR-2) using flow cytometry (A). Uptake of acetylated low-density lipoprotein $(A c-L D L)$ by EPCs (B). Colony of EPCs 8 days after peripheral blood mononuclear cell (PBMC) isolation (C). Magnification $\times 10$. VEGFR, Vascular endothelial growth factor receptor. 


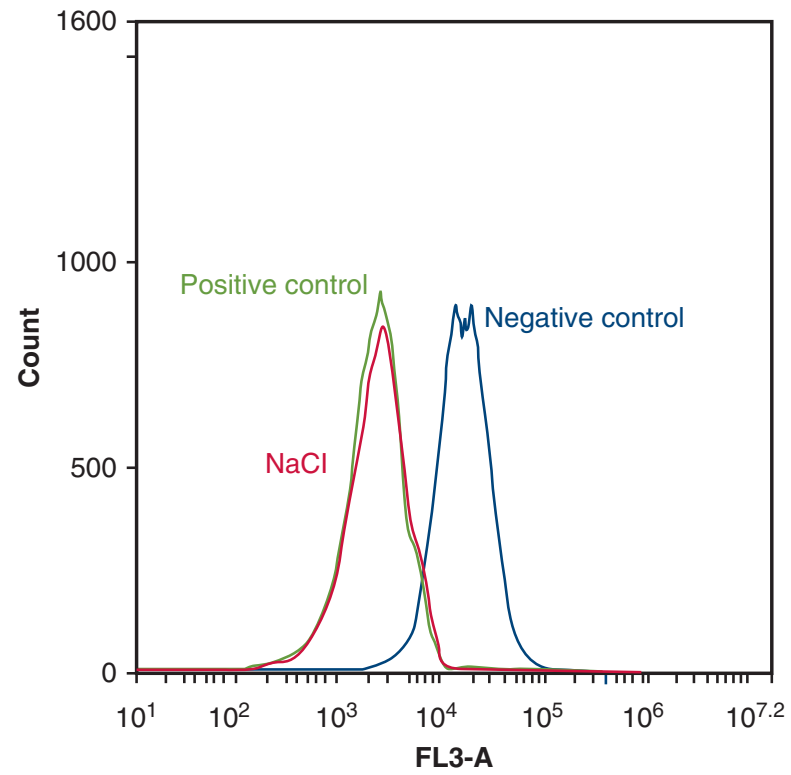

FIGURE E2. Endothelial progenitor cell $(E P C)$ viability after saline resuspension. Positive control represents EPCs resuspended in cell culture media, negative control represents permeabilized EPCs (resuspended with Cytofix/Cytoperm [Becton Dickinson, Franklin Lakes, NJ]), and $\mathrm{NaCl}$ represents EPCs resuspended in $\mathrm{NaCl}$. Ten minutes after their resuspension, a viability staining solution (7AAD) was added to the cells and its fluorescence was analyzed using flow cytometry. FL-3 corresponds to 7AAD fluorescence (Becton Dickinson); 7AAd incorporation between positive control and $\mathrm{NaCl}$ condition did not differ, showing no cell death after saline resuspension $(\mathrm{n}=3)$.

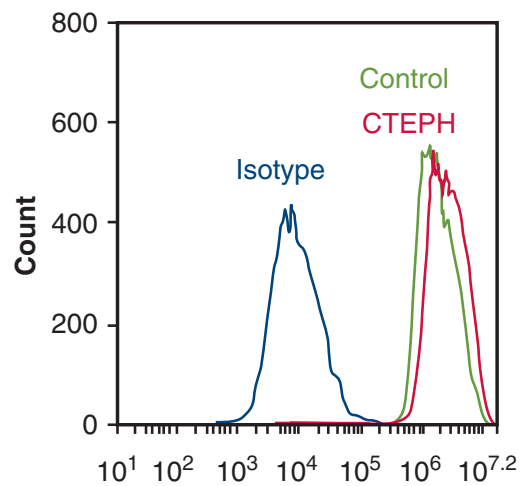

A

FL1-A

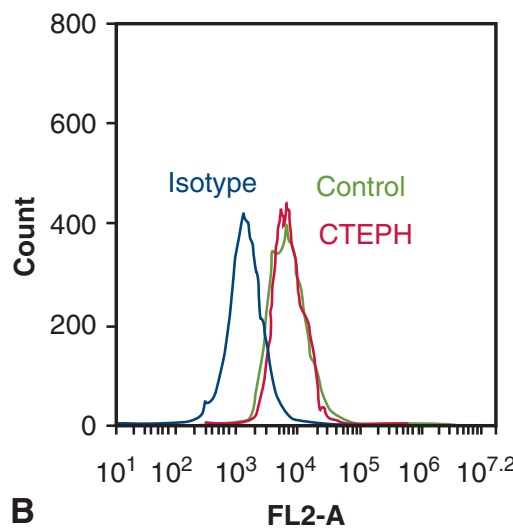

FL2-A

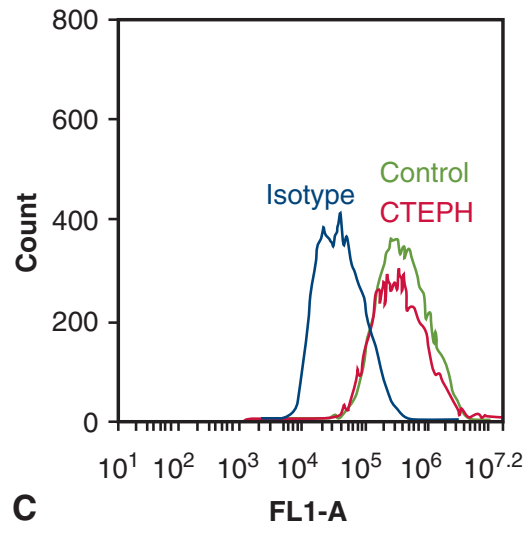

FL1-A

FIGURE E3. Phenotypic characterization of endothelial progenitor cells $(E P C S)$ before and after the establishment of chronic thromboembolic pulmonary hypertension (CTEPH): expression of the following markers: CD31 (A), CD144 (B), and VEGFR-2 (C). VEGFR, vascular endothelial growth factor receptor. 

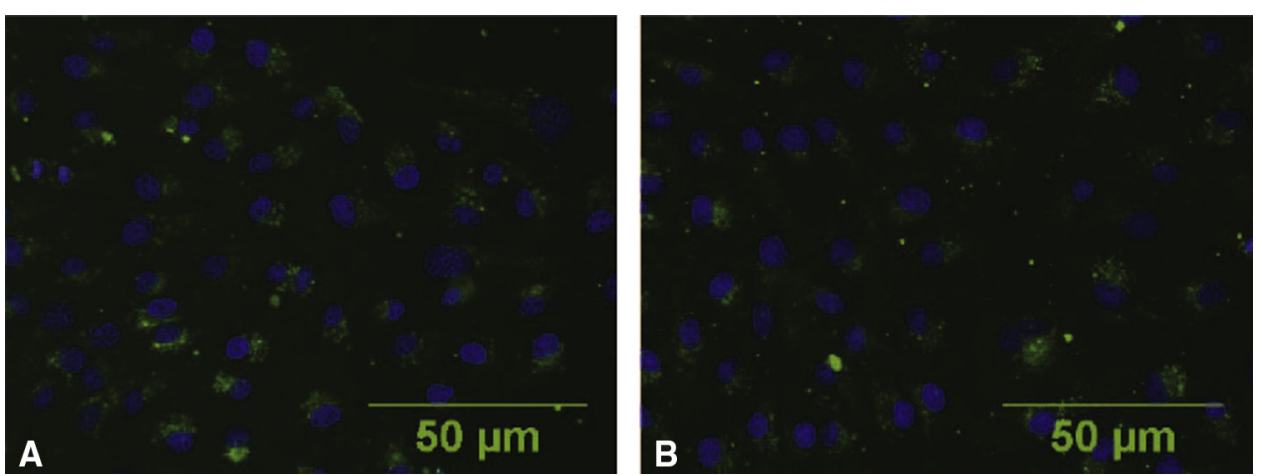

FIGURE E4. Incorporation of acetylated low-density lipoprotein by endothelial progenitor cells isolated before (A) and after (B) the establishment of chronic thromboembolic pulmonary hypertension.

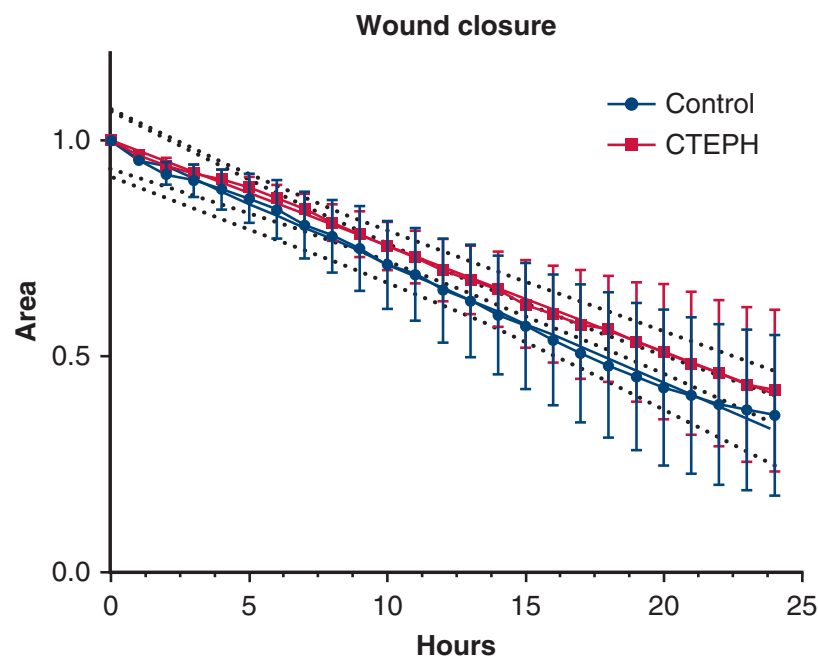

FIGURE E5. Wound closure by migration and proliferation of endothelial progenitor cells isolated before and after the establishment of chronic thromboembolic pulmonary hypertension $(C T E P H)$. 

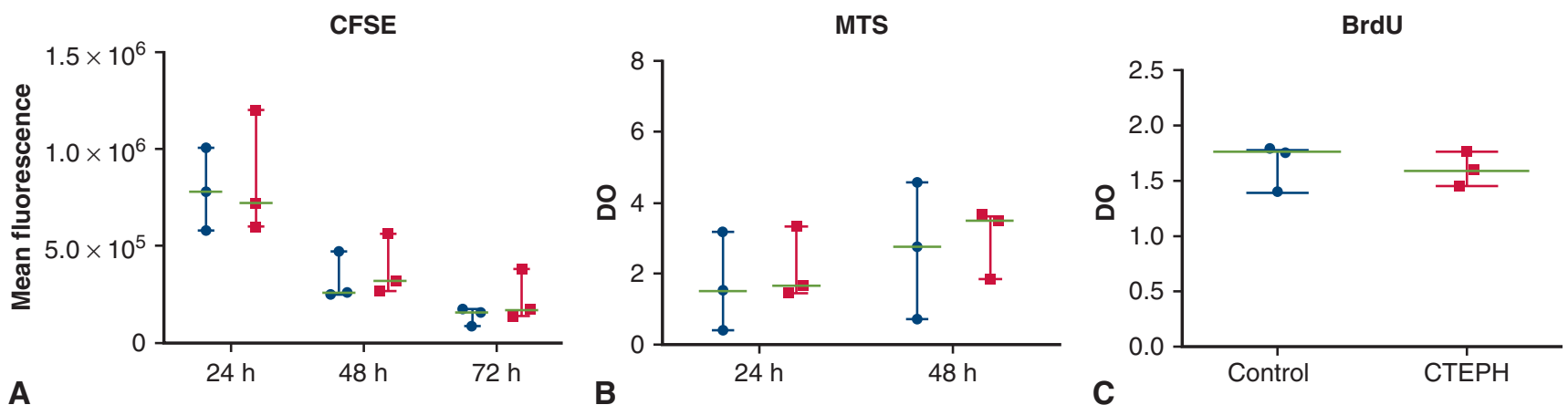

FIGURE E6. Proliferation of endothelial progenitor cells (EPCs) isolated before and after the establishment of chronic thromboembolic pulmonary hypertension $(C T E P H)$ by measuring dye dilution during their proliferation (carboxyfluorescein succinimidyl ester; Vybrant CFDA SE Cell Tracer Kit, ThermoFisher Scientific, Waltham, Mass) (A), by analyzing their metabolic activity (MTS assay) (B), and their proliferation using a 5-bromo-2-deoxyuridine $(B r d U)$ test $(\mathrm{C})$.

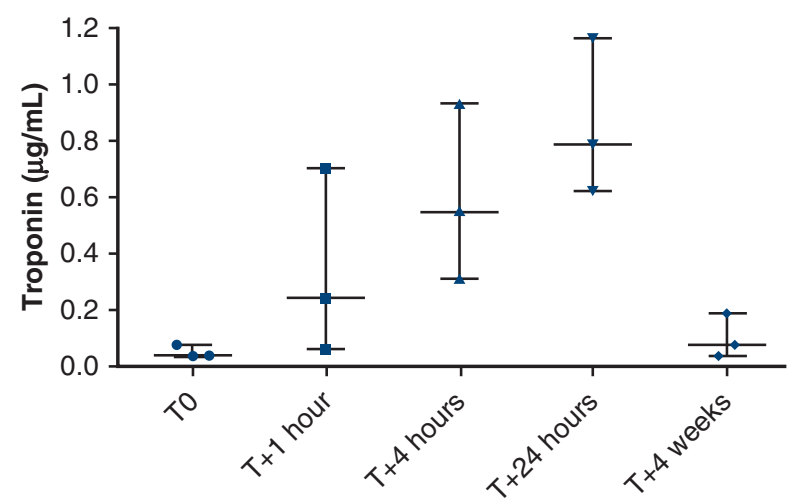

FIGURE E7. Cardiac troponin I level before and 1, 4, and 24 hours and 4 weeks after right intracoronary endothelial progenitor cell administration. 

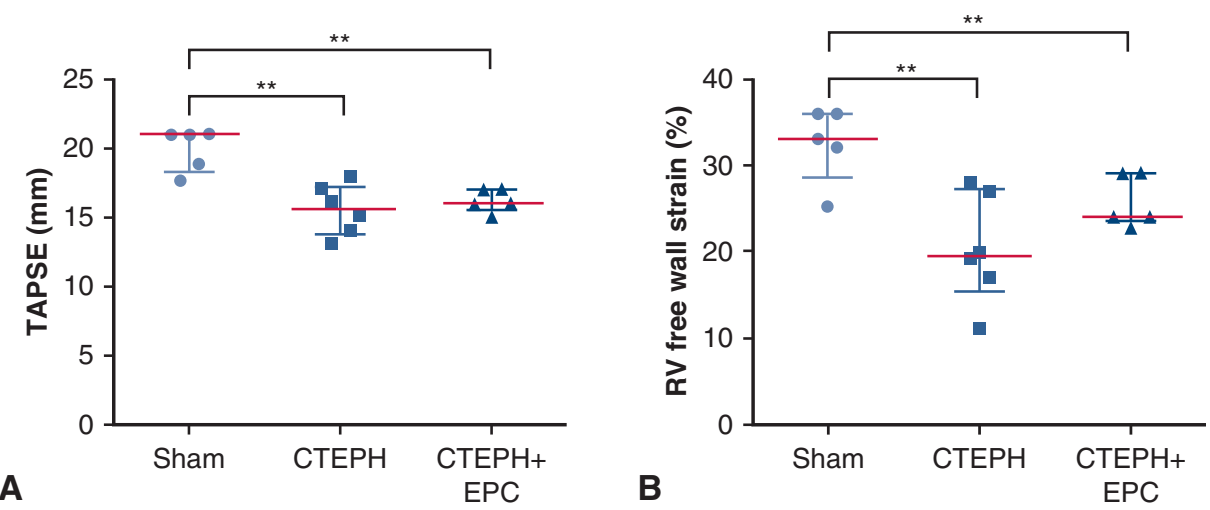

FIGURE E8. Right ventricle $(R V)$ function. At T10, there was no difference between the chronic thromboembolic pulmonary hypertension $(C T E P H)$ and chronic thromboembolic pulmonary hypertension and endothelial progenitor cell infusion $(C T E P H+E P C)$ groups regarding echographic parameters such as tricuspid annular plane systolic excursion (TAPSE) (A) and RV free wall strain (B). **P<.01.

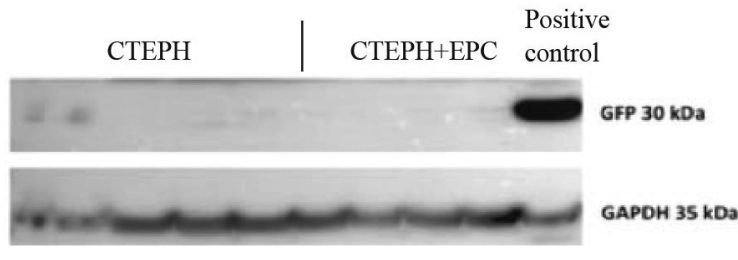

FIGURE E9. Analysis of GFP expression in right ventricle (RV) in Western blot analysis 4 weeks after right intracoronary administration of the endothelial progenitor cells (EPCs). CTEPH, chronic thromboembolic pulmonary hypertension; $C T E P H+E P C$, chronic thromboembolic pulmonary hypertension and endothelial progenitor cell infusion; $G F P$, green fluorescent protein; GAPDH, glyceraldehyde-3-phosphate dehydrogenase. 